\title{
Does Immigration Crowd Natives Into or Out of Higher Education?
}

\author{
Osborne Jackson
}

\begin{abstract}
:
This paper investigates the impact of immigration on the college enrollment of U.S. natives. Many studies have focused on the effect of increased demand for schooling by immigrants on the enrollment of natives. However, changes in immigrant labor supply may also affect native enrollment by changing local market prices. Using U.S. Census data from 1970 to 2000, I find that state-level increases in the number of immigrant college students do not significantly lower the enrollment rates of U.S. natives. On the contrary, state-level increases in the ratio of unskilled immigrant workers to skilled immigrant workers significantly raise native enrollment rates. These findings suggest that the demand for college is sensitive to wage rates and that college slots are flexibly supplied over a decadal time horizon.
\end{abstract}

\section{Keywords: immigration, native college enrollment, labor market, crowd out JEL Classifications: J24, J61, J22, J23, H75}

Osborne Jackson is an economist in the New England Public Policy Center in the research department of the Federal Reserve Bank of Boston. His email address is osborne.jackson@bos.frb.org..

I would like to thank John Bound, Charlie Brown, Wenjie Chen, John DiNardo, Sue Dynarski, Ann Ferris, Jeff Groen, Jennifer Hunt, Laura Kawano, Owen Kearney, Brian Kovak, Stephan Lindner, Ryan Michaels, Zoë McLaren, Todd Pugatch, Brian Rowe, Matt Rutledge, Dan Silverman, Jeff Smith, Gary Solon, Kevin Stange, Bob Triest, and seminar participants at several institutions and conferences for their helpful comments. I gratefully acknowledge generous fellowship support while at the University of Michigan from the Ford Foundation, Rackham Graduate School at the University of Michigan, and Verne and Judith Istock via the University of Michigan. This research was also generously supported while I was at the University of Michigan by a grant from the American Educational Research Association, which receives funds for its "AERA Grants Program" from the National Science Foundation and the National Center for Education Statistics of the Institute of Education Sciences (U.S. Department of Education) under NSF Grant \#DRL0634035.

This paper, which may be revised, is available on the web site of the Federal Reserve Bank of Boston at http://www.bostonfed.org/economic/wp/index.htm.

The views expressed in this paper are those of the author and do not necessarily reflect the views of the granting agencies, the Federal Reserve Bank of Boston, or the Federal Reserve System. All errors are my own.

This version: October 2015 


\section{Introduction}

Over the past several decades, the United States has experienced some of its largest immigrant inflows since the Great Depression. This higher level of immigration has generated significant debate on the effects of such inflows on receiving markets and natives. Focusing on the higher education market, Hoxby (1998) finds that inflows of immigrant students displace disadvantaged natives from college enrollment. Studies at other levels of education have found similar displacement effects for some, although not all, natives (Betts 1998; Betts and Fairlie 2003; Borjas 2007; Gould, Lavy, and Paserman 2009). Meanwhile, labor market studies have primarily examined the impact of immigrant labor inflows on the wages of similarly and dissimilarly skilled natives. However, findings have been mixed regarding the sign and magnitude of such wage effects (for example, Borjas 2003; Card 1990; Ottaviano and Peri 2012).

The lack of consensus among the wage studies has helped to generate a growing line of research on whether natives respond endogenously to immigrant worker inflows. ${ }^{1}$ Studies in this area have, for instance, investigated whether in response to labor immigration, natives relocate, increase their supply of labor, and specialize in occupations and tasks for which they have a comparative advantage (Card 2001, 2005; Card and DiNardo 2000; Cortes and Tessada 2011; Peri and Sparber 2009; Wozniak and Murray 2012). However, it remains unexplored whether native responses in the higher education market also contribute to the absorption of immigrants into the labor market, and how this affects equilibrium in both markets.

This paper, in a unified framework of the education and labor markets, addresses the question of whether skill level via college enrollment is another margin on which natives endogenously adjust to immigrant inflows of students and labor. There is reason to anticipate native responses to both types of immigrant inflows. Marginal benefits of higher education can be framed in terms of the skilled wage relative to the unskilled wage. Marginal costs of higher education can be thought of as college tuition and fees, net of

\footnotetext{
${ }^{1}$ Immigration analyses that, more generally, highlight general equilibrium effects of immigration are also a recently expanding area (Cortes 2008; Lewis 2011; Ortega and Peri 2009).
} 
grants and aid, and the opportunity cost (the unskilled wage). ${ }^{2}$ Relatively unskilled labor immigration may increase or "crowd in" native enrollment by raising the net benefits of college, while student immigration could decrease or "crowd out" native enrollment by lowering net benefits.

This paper's incorporation of both labor market and education market effects of immigration on native educational attainment, thereby allowing for both crowd-out and crowd-in effects, is related to a handful of other work. ${ }^{3}$ Betts (1998) acknowledges the distinct effects on native skill acquisition that heterogenous immigrant inflows may have, although he does not separately identify the effects. Eberhard (2012) and Genc (2012) both examine an endogenous native skill response to immigrant labor inflows in a general equilibrium framework, finding positive effects of immigration on native earnings and welfare. Hunt (2012) focuses on the impact of immigration on the high school completion of natives, similarly allowing for both negative and positive effects due, respectively, to resource competition in the education market and avoidance of competition from immigrant high school dropouts in the labor market. She finds evidence of both negative and positive effects, with the latter effect dominating, especially for black natives. ${ }^{4}$

This study differs from the previous research by separately identifying native human capital accumulation responses to both immigrant labor and student inflows at the college margin, where such responses may be strongest due to the high school-college wage gap. The analysis also contributes to our understanding of how local markets respond to immigrant inflows. By proposing immigration-induced market price movements as the mechanism for a native skill response, the paper takes an alternative approach to examining immigration wage effects and the structure of the labor market. The native

\footnotetext{
${ }^{2}$ While resources per student may also vary across institutions and influence the demand for higher education, this paper does not focus on such school quality differences.

${ }^{3}$ Additionally, some of this related research arose after the initial writing of this paper in 2009. Such work focuses on immigration and, for instance, on native demand for vocational programs in the construction industry (Roed and Schone 2012), the elasticity of substitution between native and immigrant labor (McHenry 2015), host-country crime when allowing for endogenous skill upgrading (Dai, Liu, and Xie 2013), and the role of income in the native education response (Denisova 2013).

${ }^{4}$ Additionally, other non-immigration studies have also linked labor and education markets to determine their joint role in alternative outcomes, such as the growth in the college wage premium (Fortin 2006).
} 
enrollment response to immigration is similarly important for understanding the structure of the higher education market and the elasticity of college supply, using a different demand shock than existing work (for example, Bound and Turner 2007). The paper also helps to evaluate the sensitivity of college demand to the relative wage of unskilled labor and college tuition/fees, adding to earlier investigations of the impact of labor and education market conditions on educational attainment (Black, McKinnish, and Sanders 2005; Dynarski 2003; Kane 1999; Neumark and Wascher 1995).

I first outline a dual-market, supply-demand model that forms predictions on the reduced-form crowding effects of immigration on native college enrollment. The model also illustrates the underlying structural relationship of the crowding effects to market prices. The next sections of the paper describe the data and empirical strategy used to analyze these effects, including the approach used to isolate the exogenous component of immigrant inflows. The final sections of the paper present estimates of immigration's effect on native enrollment and discuss the sensitivity and implications of these estimates.

A key finding of this paper is that while state-level increases in the number of immigrant college students do not significantly lower native college enrollment rates, increases in the ratio of unskilled immigrant workers to skilled immigrant workers within a state do significantly raise rates. Thus, these results provide indirect evidence of market price effects of immigration on natives. However, while the model and empirical evidence suggest that inflows of unskilled immigrant labor do lower the relative unskilled wage, they also show that this effect is mitigated by the positive enrollment response of natives. Crowd-in coupled with a lack of crowd-out is shown to imply that the native response arises primarily from the wage-sensitivity of college demand and the high elasticity of college supply, rather than from large market price effects. Consistent with this assertion, the crowd-in effect is driven largely by young natives, who may be most sensitive to college returns, and is also moderately greater for natives on the margin of public school attendance, where enrollment slots are more flexibly supplied.

The remainder of the paper is organized as follows: section 2 outlines the conceptual 
framework motivating estimation. Section 3 describes the data used for analysis, while section 4 explains the empirical strategy. Section 5 presents the main results and section 6 examines the sensitivity of those results. Section 7 explores the implications of the findings, and finally, section 8 concludes.

\section{Conceptual Framework}

I use a dual-market, supply-demand framework to model the impact of heterogenous immigrant inflows on native college enrollment. Native crowd-in and crowd-out from immigration occurs in the static model via the interaction of the labor and higher education markets and movements in prices that affect native skill choice. I focus on a graphical presentation of the model that captures much of its intuition (a more detailed discussion and version of the model can be found in the appendix).

The geographic boundary of the local labor and higher education markets is assumed to be a state. ${ }^{5}$ I focus on the impact of immigration into each of these two markets for a given state, ${ }^{6}$ still allowing for out-migration from states by natives or immigrants. Individuals are considered skilled if they have at least some college education and are considered unskilled otherwise. Natives acquire skill domestically in the model, while immigrants may either acquire skill in the United States or in their home country before migrating. ${ }^{7}$

As mentioned earlier, the marginal benefits of college are the skilled wage relative to the unskilled wage, while the marginal costs of college are tuition/fees and the unskilled wage (the opportunity cost). Thus, in the college market, both the supply of and the demand for college enrollment are potentially sensitive to changes in the unskilled wage relative

\footnotetext{
${ }^{5}$ As Bound et al. (2004) discuss, because funding decisions at public institutions occur primarily at the state level, there is support for using the state as the appropriate geographic boundary of these markets. Washington, D.C., will be excluded as it is an atypical market with more flexible boundaries for both labor and educational purposes.

${ }^{6}$ Thus, state-specific notation is suppressed in all versions of the model.

${ }^{7}$ Thus, foreign-born individuals must decide whether to immigrate for college and/or employment. Jackson (2010) claims that immigrants make this college/employment decision jointly and explores whether cross-country differences in educational quality and informational asymmetries affect that choice.
} 
to the skilled wage and college tuition/fees. ${ }^{8}$ Meanwhile, the supply of and demand for relatively unskilled labor (that is, the ratio of unskilled workers to skilled workers) in the labor market are potentially sensitive to changes in the relative unskilled wage only. The relative supply of unskilled labor is determined by equilibrium college enrollment and the retention of a state's college students in its labor market, ${ }^{9}$ labor immigration and native migration, and the sensitivity of labor supply to the relative unskilled wage. ${ }^{10}$

Figures $1 \mathrm{a}$ and $1 \mathrm{~b}$ depict the impact on equilibrium native college enrollment of two types of immigrant inflows. In Figure 1a, an exogenous inflow of relatively unskilled immigrant labor increases the equilibrium relative supply of unskilled labor from $L$ to $L^{\prime}$ and lowers the relative unskilled wage from $w$ to $w^{\prime}$. This decrease in the relative wage return to being unskilled is associated with an equilibrium increase in college demand, which raises total enrollment from $E$ to $E^{\prime}$ and tuition/fees from $f$ to $f^{\prime}$. Comparing the new equilibrium at point $B$ to the old one at point $A$, native enrollment increases from $E_{N}$ to $E_{N}^{\prime}$. In other words, the model predicts that increases in relatively unskilled immigrant labor will crowd natives into college enrollment.

In Figure 1b, an exogenous inflow of immigrant students increases the demand for higher education. This increases tuition/fees and induces some natives to refrain from enrolling in college. Additionally, if the enrolled immigrant students join the local labor market as skilled labor, this decreases the equilibrium relative supply of unskilled labor and raises the relative return to being unskilled. In equilibrium, these effects result in total enrollment increasing from $E$ to $E^{\prime}$ and tuition/fees rising from $f$ to $f^{\prime}$. These changes in the higher education market are associated with a decrease in the relative supply of unskilled labor from $L$ to $L^{\prime}$ and a rise in the relative wage for unskilled labor from $w$ to $w^{\prime}$. Again comparing the new equilibrium at point $B$ to the old one at point $A$,

\footnotetext{
${ }^{8}$ Without loss of generality, I use the relative unskilled wage rather than the relative skilled wage to aid in later interpretation. Also, for simplicity, I focus on price sensitivity rather than on the roles that unemployment or college quality may also have on native enrollment.

${ }^{9}$ Bound et al. (2004) estimate that approximately 30 percent of students who attend college in a state remain there for employment in the long run.

${ }^{10}$ Labor supply sensitivity to the relative wage rate of the unskilled here reflects within-state outside options and the marginal utility of leisure, as well as the sensitivity of interstate migration to the relative wage.
} 
native enrollment here, contrary to total enrollment, decreases from $E_{N}$ to $E_{N}^{\prime}$. Therefore, increases in the number of immigrant students are predicted to crowd natives out of college enrollment.

In addition to these sign predictions, the magnitudes of the above comparative statics from the immigrant shocks are also of interest. The magnitudes depend on demand and supply elasticities in the labor and college markets, which determine how much prices (that is, wages and tuition/fees) are affected by immigrant inflows, as well as on the sensitivity of the demand for college by natives to changes in those prices. Let $\beta$ and $\alpha$ represent the sensitivity of enrollment demanded by natives to inflows of relatively unskilled immigrant labor and immigrant students, respectively, in equilibrium. Then, as the appendix details, the following can be derived for those crowd-in and crowd-out elasticities:

$$
\begin{aligned}
& \beta=\left(-\epsilon_{w L}\right)\left(\eta^{N}\right)+\left(-\epsilon_{f L}\right)\left(\phi^{N}\right) \in[0, \infty) \\
& \alpha=\left(-\epsilon_{w E}\right)\left(\eta^{N}\right)+\left(-\epsilon_{f E}\right)\left(\phi^{N}\right) \in[-1,0]
\end{aligned}
$$

where $\eta^{N}$ and $\phi^{N}$ are, respectively, the relative unskilled wage and tuition/fee elasticities of demand for college enrollment by natives. Parameters $\epsilon_{w L}$ and $\epsilon_{f L}$ are elasticities of relative unskilled wages and tuition/fees to exogenous inflows of relatively unskilled immigrant labor, while $\epsilon_{w E}$ and $\epsilon_{f E}$ are elasticities of the sensitivity of relative unskilled wages and tuition/fees to exogenous inflows of immigrant students.

Both $|\beta|>|\alpha|$ and $|\beta|<|\alpha|$ are possible, depending on structural parameter values. The lower bound on $\beta$ occurs for several scenarios, such as perfectly inelastic college supply or frictionless labor mobility across states, while the upper bound on $\beta$ requires perfectly inelastic labor demand, perfectly elastic college supply, very large immigrant population shares, and immobile labor with no labor supply sensitivity to wage changes. The upper bound on $\alpha$ occurs when there is perfectly elastic college supply combined, for instance, with perfectly elastic labor demand, while the lower bound on $\alpha$ simply 
requires perfectly inelastic college supply. This highlights the fact that markets with a more flexible supply of college enrollment slots, such as those with a larger proportion of two-year and four-year public universities (Bound and Turner 2007), should experience both amplified crowd-in effects and diminished crowd-out effects.

A key assumption made throughout the model to allow for a causal interpretation of the crowding parameters is that the state-level immigrant inflows are exogenous. However, variation across states, time, or within states over time in local labor and college market conditions may be confounded with variation in immigrant flows. This would bias estimates and misinform interpretation of the impact of immigrant flows on native college enrollment.

For instance, outward shifts in the demand for relatively unskilled labor tend to lower native college enrollment, but may also be associated with inflows of unskilled immigrant workers who are choosing markets with good prospects. As a result, measurements of the crowd-in effect would be downward biased, as increases in relatively unskilled immigrant labor would appear to cause decreases (or else, mitigated increases) in native enrollment. More generally, correlations between immigrant inflows and relative labor demand or college supply can bias each of the crowding estimates upward or downward, depending on the signs of the correlations. The magnitude of such bias depends on how strongly correlated the immigrant flows are with labor demand or college supply.

Another possible source of bias is the existence of exogenous shifts in the demand for college enrollment by natives that are correlated with immigrant inflows. Growth in the native population, for example, increases native demand for college enrollment and likely varies across states, time, or both, for a number of reasons (for example, persistent climate differences between states). If immigrants tend to locate in states where such native population growth is occurring, it may lead to a spurious relationship between immigrant inflows and increases in native enrollment.

The model thus highlights problematic sources of identifying variation in measuring the crowding effects it predicts will occur from exogenous immigration (see the appendix 
for more information). These potential biases help to motivate the estimation strategy of the paper, discussed later.

\section{Data}

The analysis uses population samples from the Integrated Public Use Microdata Series (IPUMS) of the decennial U.S. census for the 1970-to-2000 period (Ruggles et al. 2009). All individuals are classified as either immigrants or natives. An immigrant is defined as an individual born abroad who is currently either a non-citizen or a naturalized citizen. ${ }^{11}$ I oversample immigrants such that the census data on immigrants constitutes 1 percent population samples in 1970 and 5 percent population samples in 1980-2000, while data on natives are 1 percent population samples over the entire data range 1970-2000. The sample consists of working-age individuals ages 18 to 64 not living in group quarters (for example, correctional facilities) unless those quarters are schooling-related (for example, boarding schools). All 50 U.S. states are included (Washington, D.C. is excluded) and I define states as the local labor and higher education markets. There are 7,400,855 individual-level observations, consisting of 2,319,597 immigrants and 5,081,258 natives.

To create a pseudo-panel for each state $j$ and year $t$, I aggregate these data over individuals in each state-year, incorporating census individual sample weights so that the aggregates in each state-year cell are nationally representative and result in 200 stateyear observations. Skill is a binary measure, where individuals with four years of high school education or less are classified as unskilled, while individuals with some college education or more are classified as skilled, all based on census information on the highest grade attended (Jaeger 1997). ${ }^{12}$ Additionally, I use individual-level observations of 59,084

\footnotetext{
${ }^{11}$ Exceptions (that is, those coded as natives) are: a) individuals born in U.S. territories or possessions (for example, Puerto Rico, American Samoa); b) individuals born in countries (for example, Northern Mariana Islands) where they are granted automatic U.S. citizenship due to political unions with the United States, if not already deemed natives under exception (a); and c) individuals born abroad of American parents.

12 Jaeger's (1997) recommendations for coding are of particular importance here, since it is this margin of unskilled and skilled labor where differences exist between the census coding and his. Specifically, in the census consistent recode of educational attainment, respondents who are attending their first year of college or who did not complete that first year are identified with '12th grade' as their highest attended
} 
immigrants from 1960 census data in estimation in the prediction of immigrant college demand and the formation of historical immigrant enclaves (see section 4).

The top panel of Figure 2 shows the relative wage for skilled workers, or skill premium, over the sample period. Initially, the mean wage of skilled workers relative to unskilled workers fell, dropping from 1.5 times as large in 1970 to 1.4 times as large in 1980 . Median relative wages exhibited a similar, albeit less drastic, decrease. However, over the remainder of the sample period from 1980 to 2000, both the mean and median skill premia increased substantially, far surpassing their 1970 initial values. This fall and subsequent rise in the relative wages of skilled workers has been well documented in the labor literature and is a source of policy debates regarding how best to combat the rising wage inequality across skill groups (Fortin 2006).

The lower panel of Figure 2 shows that the relative supply of skilled labor measured in the census has been increasing for both natives and immigrants. ${ }^{13}$ This implies that the relative demand for skilled labor outpaced relative supply from 1980 to 2000 (Johnson 1997), generating a considerable amount of research to investigate the cause of that demand increase (Autor, Katz, and Krueger 1998; DiNardo and Pischke 1997; Krueger 1993). Figure 3 further corroborates an upward trend in individuals' skill levels over this period, as college enrollment increased steadily across various subgroups of the population.

There are a couple of points worth noting from the displayed trends. First, given the negative causal relationships outlined between immigrant skill and native skill in the model of section 2, the pattern in the lower panel of Figure 2 is somewhat surprising. However, the aggregate positive correlation between immigrant and native skill could mask a negative causal relationship, particularly at the local market level.

Additionally, given the existence of aggregate labor demand movements, Figure 2 also suggests that differential labor demand trends and shifts across states are a nontrivial possibility. Such differential labor demand, as previously discussed, could confound estigrade of education, whereas, following Jaeger (1997), I categorize the highest grade attended for these individuals as 'some college.'

${ }^{13}$ This would be an overstatement of the skill increase among the foreign-born during the sample period if illegal immigrants, who tend to be undercounted in censuses, are disproportionately unskilled. 
mates of the crowd-in and crowd-out parameters. This empirical justification for one of the bias concerns of the model further emphasizes the importance of addressing any such confounding labor demand movements in estimation.

\section{Empirical Strategy}

\subsection{Setup and Selection Issues}

Development of the model requires several empirical decisions to be made in order to estimate immigrant crowd-in and crowd-out of native college enrollment (see section 2 and the appendix). These decisions lead to the following general specification to be estimated for state $j$ and year $t$ :

$$
\ln \left(\frac{\text { Native }^{C E}}{\text { Native }}\right)_{j t}=\beta \ln \left(\frac{\text { Immig }^{U}}{\text { Immig }^{S}}\right)_{j t}+\alpha \ln \left(\text { Immig }^{C E}\right)_{j t}+\omega_{j}+\phi_{t}+\varepsilon_{j t}
$$

where $C E$ is college-enrolled, $U$ is unskilled (that is, high school education or less), $S$ is skilled (that is, some college education or more), $\omega_{j}$ and $\phi_{t}$ are, respectively, state and year fixed effects, and $\varepsilon_{j t}$ is a mean-zero error.

The dependent variable $\ln \left(\frac{\text { Native }^{C E}}{\text { Native }}\right)_{j t}$ is the log native college enrollment rate for each state-year. Focusing on the native enrollment rate rather than the level addresses concerns from the model of bias due to exogenous shocks in native college demand. Native population growth absent behavorial changes in college-going would affect enrollment levels but

would not alter enrollment rates. On the right-hand side of the equation, $\ln \left(\frac{I m m i g}{I m m i g^{S}}\right)_{j t}$ represents relatively unskilled immigrant labor in a state-year, while $\ln \left(\operatorname{Immig}^{C E}\right)_{j t}$ represents college enrollment by immigrant students in a state-year. Given the model's focus on how exogenous immigrant shifts affect native college enrollment, the regressors of interest in the estimating equation are similarly specific to immigrant quantities. Empirically, another advantage of this approach is that it avoids division bias issues (Borjas 1980) often inherent in the specifications of other displacement studies (for example, Card 2005; Hoxby 1998). Nevertheless, this strategy may prompt worry since it is total labor sup- 
ply and not solely immigrant labor supply that affects wages and, consequently, native enrollment. This concern is discussed further and addressed in section 5 .

The inclusion of the dependent and independent variables in logs is consistent with the model and allows the crowding parameters $\beta$ and $\alpha$ to be interpreted as elasticities. The model predicts $\beta \in[0, \infty)$ (crowd-in) and $\alpha \in[-1,0]$ (crowd-out) when considering consistent estimates of the parameters. Regarding $\alpha$, actually, the model's prediction technically holds for the case when native college demand and immigrant college demand are specified identically, which is not the case in equation (3). As discussed earlier, it is useful to specify the dependent variable in equation (3) as a rate in order to address bias concerns. To correct for the impact of this on the meaning of $\alpha$, I run auxiliary regressions for the main results in order to recover an interpretation of $\alpha$ that is consistent with the model's displacement predictions.

Because serial correlation in native enrollment rates is likely to occur and typically biases ordinary least squares (OLS) standard error estimates downward (Bertrand, Duflo, and Mullainathan 2004), I cluster standard errors by state to allow for an arbitrary variance-covariance structure within states. All specifications will also be unweighted, so that each state-year cell receives equal weight in estimation. ${ }^{14}$

Immigrants in the sample are neither randomly assigned to states nor randomly assigned to the labor or college market for a given state. Consequently, time-invariant and time-varying market conditions that differ across states and influence native college enrollment rates may also influence the location and college enrollment decisions of immigrants, thus affecting foreign-born labor supply and college demand. ${ }^{15}$ To remove any state-level, time-invariant factors, I re-write equation (3) in first differences. The resulting general specification to be estimated is as follows:

\footnotetext{
${ }^{14} \mathrm{An}$ alternative would be to weight observations by the square root of the underlying sample population for each state-year, presumably to decrease the influence of small-sample, high-variance observations. However, a Breusch-Pagan test for heteroskedasticity on such a specification strongly rejects the null hypothesis of homoskedasticity, suggesting that there is a nontrivial group error component to the stateyear data and that weighted estimation actually worsens heteroskedasticity rather than eliminating it (Dickens 1990).

${ }^{15}$ Cadena (2013), for instance, finds evidence that immigrants endogenously select their destination based in part on its labor market conditions.
} 


$$
\Delta \ln \left(\frac{\text { Native }^{C E}}{\text { Native }}\right)_{j t}=\beta \Delta \ln \left(\frac{\text { Immig }^{U}}{\text { Immig }^{S}}\right)_{j t}+\alpha \Delta \ln \left(\text { Immig }^{C E}\right)_{j t}+\Delta \phi_{t}+\Delta \varepsilon_{j t}
$$

where the state fixed effect, $\omega_{j}$, has now been differenced-out.

Estimation of equation (4) by OLS still may not lead to unbiased estimates of $\beta$ and $\alpha$ if immigrants select which markets to participate in based on time-varying unobservable shocks, inducing a correlation between $\Delta \varepsilon_{j t}$ and both $\Delta \ln \left(\frac{I m m i g}{I m m i g^{S}}\right)_{j t}$ and $\Delta \ln \left(\text { Immig }^{C E}\right)_{j t}$. For instance, as discussed in section 2, if unskilled immigrant labor tends to locate in areas that experienced a positive labor demand shock, $\hat{\beta}$ will be biased downward and crowd-in will be underestimated. Similarly, if immigrant students tend to locate in areas where there was a positive college supply shock, $\hat{\alpha}$ will be biased upward and crowd-out will be underestimated. Meanwhile, if immigrants to a given location that are on the margin of college enrollment or labor force participation tend to enroll when the area has experienced a negative labor demand shock or positive college supply shock, $\hat{\alpha}$ will again be biased upward. If they tend to join the labor force when the area has experienced a negative college supply shock or positive labor demand shock, $\hat{\beta}$ will again be biased downward.

Although the previous scenarios bias against finding crowd-in or crowd-out, more problematic biases remain a possibility. Immigrant students may opt for markets where a positive labor demand shock occurs because they believe it will improve their post-college employment prospects, biasing $\hat{\alpha}$ downward and overestimating crowd-out. Meanwhile, unskilled immigrant workers, possibly with college-age or younger children, might prefer markets where college supply is expanding, leading to upward-biased $\hat{\beta}$ estimates and overstating crowd-in. ${ }^{16}$ If this type of selection is occurring, it may reflect more long-term market selection on the part of immigrants, as both scenarios exhibit forward-looking behavior and longer time horizons.

\footnotetext{
${ }^{16}$ Higher social returns to college education in areas with larger stocks of skilled labor (for example, Moretti 2004) might also induce a positive correlation between college supply and unskilled immigrant labor, with or without young children.
} 
I attempt two methods to address such market selection by immigrants, beginning first with non-random selection of labor vs. college markets for a given location ("nonspatial selection"). I would like to determine which immigrant inflows contribute to labor supply vs. college demand without using actual labor force participation and enrollment status, which are affected by labor demand and college supply movements. To achieve this, I predict in-sample immigrant college demand using consistent estimates from a logit model of immigrant enrollment using pre-sample data (to be further discussed). These predictions are then utilized to determine how to allocate observed immigrant inflows to either immigrant labor supply or immigrant college demand.

Secondly, I turn to non-random "spatial selection" of local markets by immigrants. To address this, I utilize two-stage least squares (2SLS) estimation that exploits geographic variation in historical immigrant enclaves as instruments. Under certain assumptions (discussed later in detail), these instruments further isolate the exogenous component of immigrant inflows from endogenous flows that are correlated with unobserved movements in labor demand and college supply. ${ }^{17}$

Lastly, measurement error in the immigrant inflows may occur in the census data. Mismeasurement of immigration due to small immigrant inflows and/or unobserved inflows of undocumented immigrants will lead to biased crowding estimates. Regarding the former, because immigrants account for less than 10 percent of the population in most of the sample period, small flows will be prevalent, particularly in certain states. This results in a higher likelihood of measurement error, which, if classical, should lead to attenuation bias in both $\hat{\beta}$ and $\hat{\alpha}$ (Aydemir and Borjas 2011). Regarding undocumented immigration, if legal and illegal immigrant flows of a given type (that is, labor or students) are positively correlated, and if illegal immigrant inflows cause similar price effects, this will result in an upward bias in $\hat{\beta}$ and a downward bias in $\hat{\alpha}{ }^{18}$

\footnotetext{
${ }^{17}$ It should be noted that 2SLS alone, if valid, would be sufficient to address both spatial and nonspatial selection. It should therefore purge estimation of any residual, non-spatial endogeneity not already addressed by the logit model of immigrant college demand. However, if both types of selection are reasonably severe, OLS estimates addressing neither type may be uninformative due to large biases, providing support for the current approach to address biases sequentially. Table 1 in section 5 assesses the former approach to the OLS estimates and indeed finds the combined bias to be substantial.

${ }^{18}$ Hanson (2006) discusses evidence that illegal immigrants are already represented to a degree in official
} 


\subsection{Predicting Immigrant Student and Labor Inflows}

To exogenously determine which immigrants contribute to college demand, I use 1960 census cross-section data on immigrants to run a logit model of college enrollment on individual characteristics as follows, for individual $i$ in state $j$ :

$$
\text { Immig }_{i j}^{C E}=\vartheta_{0}+\vartheta_{1} \text { Age }_{i j}+\vartheta_{2} \text { Age }_{i j}^{2}+\vartheta_{3} \text { Female }_{i j}+\text { Race }_{i j}^{\prime} \vartheta_{k}+\text { Country }_{i j}^{\prime} \vartheta_{h}+\varepsilon_{i j}
$$

where Age is age in years, Female is a dummy variable for women, and Race and Country are vectors of race/ethnicity and country dummies, respectively.

As shown in the appendix, if market shocks are not correlated with any of these chosen characteristics, equation (5) will consistently estimate how each of the covariates affects college enrollment via a change in underlying college demand. Using the coefficient estimates, I predict enrollment out of sample for 1970 to 2000 and classify immigrants during the period into quintiles based on these predicted values. The highest quintile ${ }^{19}$ individuals are designated as immigrant students, while immigrants in the lowest four quintiles are designated as immigrant labor. In the latter case, skill levels are then determined, using actual educational attainment information, which is no longer endogenous given that these individuals are assumed to no longer be acquiring human capital.

One caveat with this procedure is that the observed geographic variation of the immigrant covariates from 1970 to 2000 is still subject to confounding market shocks from labor demand and college supply. This implies that this approach would, at best, only be able to address non-spatial selection. Two-stage least squares estimation will remain necessary to address spatial selection of immigrants, as well as any residual non-spatial selection not purged in the OLS estimates. By not relying on 2SLS alone to address both types of selection, we can thus learn more from the OLS estimates than we could if the

household surveys like the U.S. Census, which would tend to diminish this bias. Moreover, because the omitted variables in this case are still immigrant-related, an alternative to classifying this as bias would be to reinterpret the estimated crowding parameters as reflecting both legal and illegal immigration.

${ }^{19}$ This is a purposely conservative allocation. Observed immigrant enrollment during the sample period has a mean of 5 percent, notably lower than 20 percent. However, the low immigrant enrollment mean may be partly due to inelastic college supply. In the presence of perfectly elastic supply, immigrant college enrollment may have more closely approached 20 percent. 
estimates did not address either type of selection.

\subsection{Instruments}

The previous procedure, while addressing endogeneity in immigrants' choice of labor markets vs. college markets, fails to address any endogeneity in immigrants' location choices. To deal with such spatial selection and to purge estimation of any remaining endogeneity from non-spatial selection not already eliminated, I employ 2SLS estimation. The instruments use the historical, 1960 distribution of immigrants in the United States to form predictions about the flow of immigrants over the sample period, 1970 to 2000. These instruments are motivated by the idea that existing immigrant networks and enclaves are an important determinant of the location choices of prospective immigrants (Bartel 1989; Card 2001; Cortes 2008; Munshi 2003). The enclaves, by increasing cultural benefits and reducing informational and legal costs, increase the net marginal benefit of migration into U.S. local markets for the foreign-born.

For state $j$ and year $t$, the instruments for the log changes in relatively unskilled immigrant workers and immigrant students take the following form:

$$
\sum_{h}\left(\frac{\text { Immigrant }_{h j, 1960}}{\text { Immigrants }_{h, 1960}}\right) \times \Delta \text { Immigrant_Type }_{h t},
$$

where $h$ is countries of origin included in the 1960 U.S. Census, $\frac{\text { Immigrants }_{h j, 1960}}{\text { Immigrants }_{h, 1960}}$ is the percentage of all immigrants from country $h$ in the 1960 census who were living in state $j$, and $\Delta$ Immigrant_Type $_{h t}$ is the difference between year $t$ and year $t-1$ immigrants of a given type from country $h$. The three Immigrant_Type stocks utilized are: (1) immigrant students, (2) unskilled immigrant workers, and (3) skilled immigrant workers. All three cases are the "potential" or "predicted" stocks, as determined by the logit model of equation (5), rather than the actual stocks. For example, if 15 percent of Brazilian immigrants (predicted) were living in Massachusetts in 1960, then the instrument would allocate 15 percent of the total Brazilian student inflow (predicted) between 1980 and 1990 to Massachusetts. 
The validity of these instruments and the identification strategy hinges on three assumptions, two of which are related to the two components of the instrument. First, it is assumed that any unobserved, differential market shocks between states $j$ and $j^{\prime}$ in 1960 that caused immigrants to locate in state $j$ rather than $j^{\prime}$ are uncorrelated with such relative market shocks from 1970 to 2000. In other words, suppose that, in 1960, a labor demand shock occurred in New York that was positive relative to a similar shock in Arizona. As a result, more unskilled immigrants from Russia chose to locate in New York rather than Arizona. Then, for the instrument to be valid, it cannot be the case that over the 1970-to-2000 period, all labor demand shocks in New York relative to Arizona were also positive (that is, labor demand was growing at a faster rate in New York than Arizona). If so, then the 1970-to-2000 allocations of Russian immigrants to New York and Arizona predicted by the instrument would be correlated with the 1970-to-2000 relative labor demand shocks, causing the instrument to be endogenous.

Secondly, instrument validity requires that the total source-country immigrant inflows of each type, $\Delta$ Immigrant_Type, be exogenous to such unobserved, relative market shocks between states from 1970 to 2000. For example, suppose that a 1990 labor demand shock in Arizona that was positive relative to a similar shock in New York caused some unskilled Russian immigrants to choose to locate in Arizona rather than New York. For the instrument to be valid, it cannot be the case that such a relative labor demand shock caused some unskilled Russians to immigrate to the United States who otherwise would not have, or alternatively dissuaded some unskilled Russians from immigrating, such that the total flow of unskilled Russian immigrants in 1990 was altered by the shock. ${ }^{20}$

Combined, these two assumptions form the instrument exogeneity assumption, or the exclusion restriction. Here, this restriction imposes that the only channel through which the instrument-predicted immigrant inflows affect native enrollment rates be through their impact on the endogenous immigrant inflows - namely, log changes in the number of

\footnotetext{
${ }^{20}$ This assumption might not hold if immigrants have strong preferences for certain U.S. states. If so, then market shocks involving those states may cause individuals to change their immigration plans. However, Boustan (2010) compares results from instruments that use actual migrant flows vs. those that use migrant flows predicted from source-area push factors. She finds little difference between the two sets of results, suggesting that this assumption may hold in practice.
} 
relatively unskilled immigrant workers and immigrant students. The inclusion of divisionyear fixed effects in estimation for the nine U.S. census divisions helps to ensure that the exclusion restriction holds. With the omission of such fixed effects, the restriction would be violated if some divisions' economies had been growing, due to labor demand or college supply movements, at rates different from the growth rates of other divisions since $1960 .^{21}$ The division-year effects allow the instrument's restrictions on relative market shocks to apply only within a division (for example, Arizona and New Mexico) instead of also across divisions (for example, Arizona and New York).

The other necessary assumption for instrument validity and consistent 2SLS estimation is instrument relevance, such that the immigrant flows predicted from the instruments are sufficiently related to the endogenous immigrant flows. Estimation with weakly related instruments could severely bias the crowding coefficients and lead to spuriously significant estimates (Bound, Jaeger, and Baker 1995). Typically, in the case of one endogenous variable, an F-test on the excluded instruments is used to evaluate such relevance. However, because there are two endogenous variables here and estimation will be made robust to the correlation of errors over time within a state, all 2SLS results will be reported with the Kleibergen-Paap $r k$ statistic to assess instrument relevance (Kleibergen and Paap 2006). ${ }^{22}$ The value of this test statistic will be compared with the Stock and Yogo (2005) weak instrument identification critical values. ${ }^{23}$

\subsection{Crowding Parameter Interpretation}

Assuming the 2SLS enclave instruments are valid, the econometric interpretation of the crowding parameters $\hat{\beta}$ and $\hat{\alpha}$ still remains. Although the cross-sectional unit is a state, it is an aggregation of individual native and immigrant units where agent behavior is operating. Because, as discussed in the model (Appendix), there exists a latent native

\footnotetext{
${ }^{21}$ Cortes (2008) notes the Sun Belt region as one such example.

${ }^{22}$ An alternative approach with multiple endogenous variables is the Cragg-Donald statistic (Cragg and Donald 1993). However, this statistic assumes independent and identically distributed (i.i.d.) errors and so is less appropriate given the error structure here.

${ }^{23}$ Because Stock and Yogo's (2005) critical values are constructed assuming i.i.d. errors, they will be used more conservatively in the paper to evaluate the extent of weak instruments.
} 
ability distribution in each state, this can be thought of as determining a state-specific enrollment impact of the two continuous treatments (that is, the two immigrant inflows). Since different native ability distributions across states $j$ seem probable, it is likely that there are heterogenous impacts of these treatments across states, $\beta_{j}=\bar{\beta}+\beta_{j}^{*}$ and $\alpha_{j}=$ $\bar{\alpha}+\alpha_{j}^{*}$

With a heterogenous treatment model, parameters estimated by 2SLS are often interpreted as local average treatment effects (LATEs) — namely, marginal effects for those observations induced to treatment by the instrument (Imbens and Angrist 1994). However, if the exogeneity assumption for a valid instrument in the heterogenous treatment model actually holds, ${ }^{24}$ then an average treatment effect (ATE) interpretation of the crowding parameters (or average causal response, in this case) is still valid. ${ }^{25}$ The enclave-based "cost" of immigration is known and considered by immigrants, but the native abilitybased enrollment "benefit" of the immigrant inflow treatments is known and considered by natives. Therefore, immigrants may not know both the state-specific cost and benefit of immigration. ${ }^{26}$ Under this asymmetric information assumption, the estimated crowding parameters $\hat{\beta}$ and $\hat{\alpha}$ can be interpreted as marginal effects averaged across all observations rather than as just a subset of observations.

\footnotetext{
${ }^{24}$ For example, with heterogeneous treatment effects, the exogeneity assumption relevant for the immigrant student inflow treatment (letting $\left(\operatorname{Immig}^{C E}\right)_{j t} \equiv T_{j t}$, and $\mathbf{Z}^{\prime}{ }_{j t} \equiv$ the vector of enclave instruments) would be: $E\left[\left(\alpha_{j}^{*} \Delta T_{j t}+\Delta \varepsilon_{j t}\right) \mid \Delta \phi_{t}, \Delta T_{j t}, \Delta \mathbf{Z}^{\prime}{ }_{j t}\right]=0$. In other words, substantively, the assumption is that conditional on the immigrant inflow treatment, the values of the enclave-based instruments are uncorrelated with the state-specific impact of the treatment on native enrollment rates. This contrasts with the weaker exogeneity assumption of a common treatment model: $E\left[\Delta \varepsilon_{j t} \mid \Delta \phi_{t}, \Delta T_{j t}, \Delta \mathbf{Z}^{\prime}{ }_{j t}\right]=0$.

${ }^{25}$ This is of particular interest in this case since there may be nonlinear, diminishing effects of the enclave instruments on actual immigrant inflows. This could require the inclusion of quadratic terms as additional instruments, thus making the monotonicity assumption necessary for valid LATE interpretation (Imbens and Angrist 1994) more questionable, although not necessarily violated.

${ }^{26}$ In other words, for an immigrant inflow "participation" equation, $\Delta T_{j t} \neq \iota_{1} \alpha_{j}^{*}+\iota_{2} \Delta \mathbf{Z}_{j t}^{\prime}+\Delta \phi_{t}+\varsigma_{j t}$, but rather $\Delta T_{j t}=\varpi_{1} \Delta \mathbf{Z}_{j t}^{\prime}+\Delta \phi_{t}+\varnothing_{j t}$. If immigrants did know $\alpha_{j}^{*}$, however, one could then perhaps appeal to their knowledge of the extent of immigrant-native substitutability in production to explain why the native ability distributions would matter to them in their immigration decision.
} 


\section{Main Results}

\subsection{Immigrant Student and Labor Predictions}

Table 1 displays average marginal effects from estimating college demand by immigrants in $1960 .{ }^{27}$ The full logit model in column (1) shows that being female decreases immigrant enrollment probability on average by 1.3 percentage points relative to being male. Additionally, the probability of enrollment decreases significantly with age, as well as not significantly for all of the identified race/ethnicities relative to white non-Hispanic immigrants. The logit model predicts the correct outcome for enrollees at a higher rate than for non-enrollees, and also performs better for in-sample predictions than for out-of-sample predictions, as expected. ${ }^{28}$

Column (2) shows that the linear probability model (LPM) estimated by OLS has qualitatively and often quantitatively similar results to the logit specification, although the age effects are now significantly nonlinear and some of the race/ethnicity effects are now significant. However, the indicated measures of model fit are worse for the LPM estimation except that the model performs somewhat better in predicting the number of enrollees. This is also the case for the logit model with age only in column (3), although not by a large margin. Appendix Table A2 displays average (weighted) characteristics of each quintile in the college demand index, characteristics that are qualitatively similar to the estimation results of Table 1, as expected.

There are other potential alternative models to designate immigrant students and labor. One possibility is to not distinguish immigrant inflows, presuming that students and labor have a homogeneous effect on native enrollment, contrary to the model's predictions. Alternatively, I can determine an age cutoff using the distribution of enrolled immigrants in 1960. Immigrants of age equal to or below the cutoff age are designated as immigrant students, and immigrants older than the age cutoff are designated as immigrant workers.

\footnotetext{
${ }^{27}$ Appendix Table A1 examines averages of the covariates used in specification (5) for college-enrolled and not-college-enrolled immigrants.

${ }^{28}$ Because, as Appendix Table A1 shows, the unconditional probability of immigrant enrollment in 1960 is very low, at 1 percent, this 0.01 value is used as the threshold for evaluating the logit predictions rather than the standard threshold of 0.5 (Heckman and Smith 1999).
} 
Finally, I can also use the endogenous labor force participation and college enrollment information to classify the immigrant inflows appropriately.

Table 2 displays OLS results from estimation of baseline equation (4) using the above methods to determine the immigrant inflow regressors. Column (1) shows that under the assumption of homogeneous immigrant inflows, there is no significant effect of immigration on native college enrollment rates. Column (2), the preferred method, differentiates immigrant inflows. This specification finds support for the predictions of the model, as there is both significant crowd-in and crowd-out, with elasticities of 0.26 for $\hat{\beta}$ and -0.14 for $\hat{\alpha}$.

Columns (3) to (5) show that sensible alternative methods yield quantitatively similar results to column (2). However, once endogenous labor and college market information is used in column (6), the coefficient magnitudes are severely diminished. As discussed in section 4, this suggests that non-spatial immigrant selection into the college market is negatively correlated with labor demand shifts or positively correlated with college supply shifts. Conversely, column (6) implies that non-spatial immigrant selection into the labor market is positively correlated with labor demand shifts or negatively correlated with college supply shifts. Thus, non-spatial selection bias in OLS estimation is notably reduced using the preferred method of column (2) relative to column (6).

\subsection{Descriptive Statistics}

Figures $4 \mathrm{a}$ and $4 \mathrm{~b}$ show that there is substantial geographic variation in the predicted immigrant labor and immigrant student variables over the sample period. Nearly all states saw large decreases (some over 100 percent in magnitude) in the relative labor supply of unskilled immigrant labor, with the exception of Idaho and Kansas, which experienced small increases. Meanwhile, there were widespread increases in the number of immigrant students over the sample period, especially in the Sun Belt region, with the sole exception of Vermont, which had a small decrease. Both figures are thus consistent with the upward skill trends shown in Figures 2 and 3. 
The precision of the separately estimated coefficients for crowd-in and crowd-out relies on the degree of collinearity between the predicted immigrant worker and student flows. Figure 4c shows that precise identification (at least, for OLS; additional factors matter for 2SLS) does not come from large immigrant flow states such as California, New York, and Florida, but rather from much smaller flow states like Nebraska. This will be explored further in the main estimates.

A caveat to Figures $4 \mathrm{a}$ to $4 \mathrm{c}$ is that they do not purge the immigrant labor and student flows of macro-level, national variation. They also do not remove the portion of variation in the immigrant flows to each state that is time invariant. If such variation reflects unobservables that are also correlated with native college enrollment rates, using it for parameter identification will lead to biased immigrant crowding estimates.

Table 3 shows that, in addition to the statistically significant change that each dependent and independent variable experienced over the sample period, year and state-specific variation in the variables is substantial. For instance, 14 percent of the variation in native college enrollment rates differs across census years but not across states, while 60 percent of the variation differs across states but is time-invariant. This leaves 26 percent of the variation differing within states over time, generally accounting for one-fifth to one-quarter of the total variation across all variables of interest. As equation (4) notes, because all estimates will account for state and year fixed effects, the identifying variation is only from within states over time.

\subsection{Baseline OLS and 2SLS Estimates}

Table 4 shows the estimates from the first-stage regressions for relatively unskilled immigrant workers and immigrant students. In both columns (1) and (2), historical immigrant shares predict relatively small inflows of actual immigrants but with coefficients that are generally statistically significant. This is reflected in the large $F$-statistics from tests showing that the coefficients on the instruments are jointly equal to zero, both above 
critical values for weak instruments. ${ }^{29}$ Both columns use quadratic specifications to allow for nonlinear effects of historical immigrant enclaves on immigrant flows. In each case, these nonlinear effects are significant, and the level and quadratic term for a given covariate are of opposite signs, providing support for the existence of diminishing net marginal benefits to the immigrant network. ${ }^{30}$ Allowing for nonlinear effects is also sensible based on the log functional form of the endogenous variables being instrumented. For instance, alternatively dropping the second-order regressors in Table 4, taking logs of the first-order instruments, and re-running column (1) results in the undesirable loss of nearly a third of the observations but still results in significant enclave coefficients and a first-stage $F$-statistic of $8.6 .^{31}$

Table 5 presents the main OLS and 2SLS estimates. Column (1) is identical to column (2) from Table 2, with one exception. For all specifications, as discussed in section 4 , auxiliary regressions were also run where the dependent variables are $\Delta\left(\frac{\text { Native }}{\text { Native }}\right)_{j t}$ and $\Delta\left(\frac{\text { Immig } C E}{\text { Native }}\right)_{j t}$. The last row of Table 5 reflects the ratio of crowd-out coefficients from those auxiliary specifications, which can be interpreted as the number of natives who disenroll for every immigrant enrollee. This displacement interpretation, not directly discernible from the crowd-out coefficient $\hat{\alpha}$ alone, is more closely aligned with the magnitude prediction for $\hat{\alpha}$ from the model, as displacement should be bounded between -1 and $0 .{ }^{32}$

In the OLS results, there is no statistically significant evidence of crowding once division-year fixed effects or state-specific linear trends are included in columns (2) and

\footnotetext{
${ }^{29}$ The Stock and Yogo (2005) critical values for the maximal actual size of a 5 percent Wald test of the six immigrant enclave instruments jointly being equal to 0 are 29.18, 16.23, and 11.72 for maximal test sizes of 10,15 , and 20 percent, respectively. The $F$-statistic on the six immigrant enclave instruments thus exceeds the first critical value for both relatively unskilled immigrant worker inflows and immigrant student inflows.

${ }^{30}$ In addition to such diminishing returns, nonlinearities may result from a minimum threshold an enclave must reach in size before it has value to a new migrant entrant (that is, a network externality).

${ }^{31}$ Cortes (2008) similarly allows for such nonlinearities in her first-stage analysis, reporting results for both log-log and quadratic specifications and likewise opting for the latter. In this study, when the enclave-based instruments are specified as regressors only in terms of first-order levels rather than in logs or quadratic terms, the instrument coefficients are generally not statistically significant and have low first-stage $F$-statistics.

${ }^{32}$ In the presence of any confounding biases, however, displacement estimates could lie outside of these bounds.
} 
(3). In both cases, compared with the results in column (1), the magnitude of both crowding coefficients is also reduced. The crowd-in elasticity decreases from 0.263 to 0.137 with division-year effects, and to 0.170 with state trends, while the crowd-out elasticity decreases from -0.143 to -0.087 with division-year effects, and to -0.113 with state trends.

This supports the notion that the division-year fixed effects are accounting for nontrivial bias from immigrant selection of markets across divisions in response to market shocks. The bias is upward on the crowd-in coefficient and downward on the crowd-out coefficient. Immigrant labor is dynamically locating in divisions with growing college prospects (in terms of college supply shifts), while immigrant students are choosing divisions with growing employment opportunities (in terms of labor demand shifts). As discussed in section 4, this may mean that immigrant relocations across divisions are made with longer-term prospects in mind. A similar interpretation holds for the comparison to column (3) except that the immigrant selection is across states rather than divisions, and based on state market trends rather than division shocks.

From the coefficient magnitudes, it appears that immigrant selection is occurring more at the division level than the state level. ${ }^{33}$ Additionally, columns (4) and (5) confirm the expectation from Figure 4c that precise OLS identification is not coming from states with large immigrant flows like California. Rather, estimation precision is coming more from states like Idaho with low correlations between the two immigrant inflows.

Turning to 2SLS estimation and comparing column (6) to column (1), both crowd-in and crowd-out estimates are larger in magnitude. This supports the idea that, in terms of responses to state-year shocks, immigrant labor is endogenously locating in states where the labor market for them is improving, downwardly biasing the OLS estimates compared with 2SLS. Meanwhile, immigrant students are locating in states with expanding college markets, upwardly biasing the OLS estimates relative to 2SLS. Compared with the separate, first-stage $F$-statistics from Table 4, the Kleibergen-Paap rk statistic of 15.00

\footnotetext{
${ }^{33}$ Alternatively, linear trends may not be sufficient to represent the immigrant selection occurring at the state level, if such selection is a response to state-year shocks.
} 
suggests that estimation is slightly, but not prohibitively, weak. ${ }^{34}$

Once division-year fixed effects are included to strengthen instrument validity in preferred specification (7) of Table 5, the crowd-out elasticity falls to -0.04 but is no longer statistically significant, while the crowd-in elasticity of 0.33 is also smaller but still significant. In terms of displacement effects of crowd-out, although not significant, I nevertheless estimate a crowd-out ratio of -0.24 . This implies that for every four immigrants enrolled in college, one native does not enroll, which falls in a range consistent with the model as well as with other studies. ${ }^{35}$

In column (8), an $\mathrm{F}$ test fails to reject the hypothesis that the coefficients on the included state-specific linear trends are jointly zero. Furthermore, unlike the OLS regressions, column (9) shows that the 2SLS results do appear to be nontrivially identified from large immigrant flow states like California. This is not surprising given that these are the states where the historical enclaves would be expected to better predict actual immigrant inflows. However, as in OLS, exclusion of states like Idaho in column (10) tends to inflate the standard errors without significantly affecting the point estimates compared with column (6).

\subsection{Relative Supply of Total Labor}

Thus far, in terms of crowd-in effects, I have been focusing on relatively unskilled immigrant labor and how changes in this variable can affect native college enrollment rates. However, as Figure 1a and the Appendix model suggest, what affects the relative wage and subsequent native enrollment choices is shifts in the relative supply of total labor. Such shifts in total labor, while affected by immigrant inflows, may differ in magnitude

\footnotetext{
${ }^{34}$ With two endogenous variables, the Stock and Yogo (2005) critical values for the maximal actual size of a 5 percent Wald test of the six immigrant enclave instruments jointly being equal to 0 are 21.68 , 12.33, and 9.10 for maximal test sizes of 10,15 , and 20 percent, respectively. The rk statistic on the enclave instruments lies between the first and second critical values.

${ }^{35}$ In her instrumental variables specification, the significant estimates that Hoxby (1998) finds imply a crowd-out ratio ranging from -0.24 to -0.64 . Additionally, although not focusing on immigrant-native displacement, Bound and Turner (2007) find in their study of cohort crowding that a 10 percent statespecific increase in the size of the college-age population decreases the fraction attaining a BA degree by 4 percent, an elasticity of -0.4 .
} 
from shifts in immigrant labor. Thus, total labor movements may alter relative wages and college enrollment incentives differently, leading to potential bias in the crowd-in coefficient from utilizing variation in relatively unskilled immigrant labor alone.

Table 6 examines this issue, replacing relatively unskilled immigrant labor as a regressor in estimation with relatively unskilled total labor. However, there are empirical issues with this strategy that make it undesirable, despite its theoretical reasonability. First, if native labor internal migration and location choice are more sensitive to labor market conditions than immigrant labor, perhaps due to better market information, relatively unskilled total labor will be more severely correlated with labor demand movements. This will downwardly bias the OLS coefficient on total labor. Columns (1) and (2) suggest that this is the case, as the coefficient on relatively unskilled total labor is significantly negative. OLS estimates of the impact of total labor flows are therefore uninformative. ${ }^{36}$

Meanwhile, the enclave-based instruments utilized for this paper do not have strong theoretical grounding to have predictive power for natives. The fact that they are not weak in column (4) despite the low percentage of immigrants in total labor supply, raises some suspicion that perhaps immigrant enclaves are predictive of native location decisions for reasons correlated with labor demand. This would bias the 2SLS coefficients on total labor supply downward toward OLS, which is what is observed. That said, compared with column (2), the coefficient on relatively unskilled total labor in column (4), although still negative, is reduced by nearly 50 percent. Thus, despite likely downward bias due to the endogeneity of native labor supply, there nevertheless remains some evidence of the earlier, crowd-in effect on native enrollment of exogenous increases in relatively unskilled immigrant labor.

Finally, once again regarding the main estimating equation (4), the level of immigration would also certainly, other things being equal, matter in accounting for firm output levels and scale effects. However, as such scale effects would, by definition, hold relative wages constant, they are not theorized in the model to affect native incentives to either

\footnotetext{
${ }^{36}$ One possibility to address this, however, might be to run a logit model of total college demand, similar to the immigrant demand model in equation (5), to form predicted labor supplied to utilize in the OLS regressions.
} 
remain unskilled or become skilled. Thus, the level of immigration, as compared to its skill composition, should not have a large effect, if any, on native college enrollment rates. ${ }^{37}$

\section{Sensitivity Analyses}

\subsection{Native Response Heterogeneity}

The identification of a crowd-in effect and the lack of a significant crowd-out effect are suggestive of college demand that is fairly wage-sensitive and college slots that are flexibly supplied over a decadal time horizon. Table 7 explores heterogeneity in the native enrollment response to examine these hypotheses empirically, running specification (7) of Table 5 on native subgroups. First, there appear to be differential responses by age. The crowd-in effect is identical in magnitude for young natives ages 18-24, with an elasticity of 0.33 . However, it is more precisely measured, suggesting that this is the group that accounts for the statistical significance of the effect for natives ages 18-44 in Table 5, column (7). While the results are qualitatively similar for 25-34 year-old natives, the crowd-in effect is smaller in magnitude and the crowd-out effect is larger in magnitude, although neither coefficient is significant. Given equations 1 and 2, and if immigrant market price effects are similar across age groups, these results suggest that the college enrollment demand of young natives is more sensitive to changes in the relative unskilled wage and tuition/fees than the demand of older natives. For female natives, both the crowd-in and crowd-out coefficients are slightly larger in magnitude compared with the baseline estimates, although not significantly so. Nevertheless, this is consistent with more elastic enrollment demand by women than men.

Meanwhile, the model predicts that, other things being equal, as college supply becomes more elastic, the crowd-out effect should decrease in magnitude while the crowd-in

\footnotetext{
${ }^{37}$ However, to the extent that the level of immigration does matter because the model is incorrect, it remains likely that much of the variation and potential bias from that variable is accounted for by the combination of year, state (differenced out), and division-year fixed effects. This is suggested by Table 3, which shows, for instance, that 96 percent of the variation in the native population is accounted for by state fixed effects.
} 
effect increases (Appendix). Because it is expected that college supply is more elastic for public institutions (Bound and Turner 2007), the theoretical predications can be evaluated by focusing the results on public schools only. Table 7 shows that, consistent with the model, for natives on the margin of public enrollment, crowd-in is larger in magnitude compared with the baseline results, while crowd-out is smaller in magnitude. Additionally, given the decadal nature of the census data and the longer time horizon of the effects being examined here, more-elastic college supply at both public and private institutions is likely factoring into the results.

Table 8 examines the extent of an attainment response that is similar to the enrollment response. Qualitatively, the results are indeed similar. However, now the only statistically significant crowd-in response occurs for 25-34 year-olds. This may be due to the fact that attainment, unlike enrollment, is persistent. So in a given year, a significant 25-34 yearold native response may reflect both 25-34 year-olds currently experiencing immigrant inflows into their markets and 18-24 year-olds who experienced earlier immigrant inflows. Additionally, Table 8 provides some limited evidence that the marginal natives who are responding to immigration are those with less than four years of high school education. This could reflect their wages and tuition/fees being most affected by immigrant inflows, or that these natives are the most sensitive to such price changes.

\subsection{Assessing Measurement Error in Immigrant Inflows}

I turn now toward the assessment of two potential sources of measurement error in the immigrant regressors. As discussed earlier, the prevalence of small immigration inflows will increase the probability of classical measurement error, attenuating crowd-in and crowdout estimates. To explore the influence of any such error in the results, in columns (3) and (4) of Table 9 I exclude Kansas and Vermont, which have the smallest flows of exogenous immigrant labor and immigrant students over the sample period. Focusing again on the 2SLS estimates, and compared with the baseline estimates reposted in column (2), the

crowd-in elasticity increases by 0.05 , while the crowd-out elasticity, still not significant, 
decreases by 0.01 . This suggests that, while measurement error from small flows is indeed attenuating the baseline estimates, it does not appear to be doing so substantially.

Additionally, illegal immigrants may be only partly reflected in the census data and yet could represent relatively large inflows in some states, thus likely affecting native enrollment. As previously noted, if legal and illegal immigrant flows of a given type (that is, workers or students) are positively correlated and cause similar price effects on wages and tuition/fees, then the crowd-in estimate will be upwardly biased while the crowd-out estimate will be downwardly biased. To evaluate the extent of such omitted variable bias arising from incorrect measurement of immigrant flows, I exclude in columns (5) and (6) of Table 9 the border states of Arizona and New Mexico, the two border states that do not have the largest immigrant inflows. ${ }^{38}$ Upon doing so, I observe the expected changes in the crowding coefficients, as the magnitudes of both $\hat{\beta}$ and $\hat{\alpha}$ are reduced. However, the crowd-in result is still significant and remains quite close in magnitude to the column (2) baseline, implying that this source of error in immigrant measurement is not particularly problematic. The small degree of bias may be due in part to illegal status mitigating the extent of market price effects that undocumented immigrants can exert. This could result from restrictions on labor employment or college enrollment. Regardless, as noted earlier, because the omitted variables here are still immigrant-related, any bias could be reinterpreted as part of the parameter of interest, with the crowding elasticities reflecting both legal and illegal immigration.

\section{Implications}

\subsection{Aggregate Native Enrollment}

Given the preferred crowd-in estimate of 0.330 from Table 7 , specification (2), a simple counterfactual exercise can be used to assess crowd-in's role in the aggregate change

\footnotetext{
${ }^{38}$ Remaining border states California and Texas have the largest immigrant inflows in the country over the sample period. Their exclusion adversely affects the relevance of the enclave instruments to immigrant flows, so they are kept in the sample for this analysis.
} 
observed from 1970 to 2000 in mean college enrollment rates of young U.S. natives. The exercise supposes that the immigrant skill mix stayed constant over the sample period at its 1970 value. ${ }^{39}$ This is consistent with a very large counterfactual increase of 120.3 percent in the ratio of unskilled immigrant workers to skilled immigrant workers over the sample period. Such an inflow of immigrant labor would have led to a 39.7 percent increase in mean enrollment rates of young U.S. natives ages 18-24, an increase that is 18.3 percentage points larger than the observed enrollment rate increase of 21.4 percent during this period. Thus, the observed increase in the skill composition of immigrants during the latter part of the 20th century contributed to lower rates of native college enrollment than would have otherwise been observed.

This is a sizable suggested aggregate effect of crowd-in. However, as mentioned, the counterfactual change in the skill mix over the examined time period is quite large. Additionally, undercounting of undocumented, unskilled immigrants in the census data (which Table 9 implies might be an issue to some extent) could also be contributing to the aggregate crowd-in effect. Such undercounting would overstate the change in the immigrant skill mix during the sample period, resulting in an overstatement of the aggregate impact of crowd-in. Finally, the large implied aggregate crowd-in effect is undoubtedly also due to the use of a simple partial equilibrium exercise over a 30-year period when general equilibrium effects would also likely be a factor.

\subsection{Elasticities of Demand for College by Natives}

Equations 1 and 2 and the formal model in the appendix illustrate the theoretical link between the crowding parameters estimated in this paper and underlying structural parameters for the relative unskilled wage and college tuition/fee elasticities of demand for college enrollment demand by natives. It is thus useful to determine what values of these price elasticities, under certain restrictions on the remaining variables in the model, are implied by the crowd-in and crowd-out estimates.

\footnotetext{
${ }^{39}$ The actual (not predicted) 1970 immigrant (unskilled/skilled) labor force ratio is 2.4, while the actual 2000 immigrant (unskilled/skilled) labor force ratio is 1.1.
} 
Table 10 summarizes the results for $\eta^{N}$ and $\phi^{N}$ from parameterizing the model (further details in the appendix). Note from the formal model that both parameters enter into college demand negatively. Thus, although the derived elasticities are positive, increases in the relative unskilled wage and college tuition/fees both decrease native college demand, as expected. For all values of $\psi$, the tuition/fee elasticity of college supply, and $\theta$, the elasticity of substitution between skilled and unskilled labor, natives have fairly wagesensitive demand for college enrollment, as $\eta^{N}$ lies between 5.8 and 8.6. In other words, a 1 percent increase in the relative unskilled wage would decrease the rate of native college enrollment by 5.8 to 8.6 percent. At the mean enrollment rate of 9.2 percent during the sample period for natives 18-44 years old, this would result in a rate decrease of 0.5 to 0.8 percentage points.

For the low and high $\psi$ values, respectively, native college demand ranges from being tuition/fee inelastic with a $\phi^{N}$ of 0.7 , to being quite elastic with a value of 18.1. Thus, a 1 percent college tuition/fee increase would decrease the native college enrollment rate by 0.7 to 18.1 percent. However, only the 0.7 estimate is derived using a value of $\psi$ that is not purely hypothetical and so is likely more plausible. Once again, at the mean enrollment rate of 9.2 percent, this would result in a rate decrease of 0.1 to 1.7 percentage points.

This exercise indicates that for reasonable parameter values, the paper's crowding estimates suggest that native college demand is quite wage-sensitive. Kane (1999) finds that youth are fairly sensitive in their college enrollment demand to opportunity costs (that is, the unskilled wage), but insensitive to discounted earnings differentials between those with a high school degree and those with some college. Because both the opportunity cost and discounted earnings are reflected in the relative unskilled wage that is this paper's focus, the extent to which it aligns with Kane (1999) is mixed. Moreover, Kane (1999) also finds that youth college enrollment is sensitive to changes in tuition, with an elasticity of approximately -1, interpreting the combined wage and tuition results to be consistent with behavior in the presence of financing constraints. One possible explanation for the contrast in his results with those of this paper is the difference in the estimation 
time horizon. ${ }^{40}$ With this paper's longer, decadal time frame, financial constraints on college enrollment may be less binding, consistent with an increased wage sensitivity and decreased tuition/fee sensitivity of college demand.

Finally, it should also be noted that the implied elasticities of immigrant inflows on wages and tuition/fees (not shown) are non-zero but small. For instance, for the first set of values shown in Table 10 for $\psi, \theta, \eta^{N}$, and $\phi^{N}$, a 10 percent increase in relatively unskilled immigrant labor reduces relative unskilled wages by about 0.24 percent. Thus, the model and results imply that while immigrants do affect market wages, these effects need not be particularly large to result in the crowding responses observed, because of natives' sensitivity to wage changes.

\section{Conclusion}

This paper estimates how inflows of immigrant students and immigrant labor, by changing the costs and benefits of higher education, affect the postsecondary enrollment of natives. I first construct a dual-market, supply-demand model to form predictions over the effects of immigration on native skill acquisition. Using U.S. Census microdata from 1970 to 2000, I test the predictions of the model by estimating the causal impact of heterogeneous immigrant inflows into local markets on college enrollment rates of U.S. natives in those areas. To isolate the exogenous component of immigrant inflows from endogenous flows that vary with unobserved movements in labor demand and college supply, I use a model of immigrant college demand combined with two-stage least squares estimation that utilizes geographic variation in historical immigrant enclaves.

I find that a 1 percent state-level increase in relatively unskilled immigrant labor raises the rate of native college enrollment in that state by 0.33 percent. Meanwhile, a 1 percent state-level increase in immigrant college students lowers that state's native enrollment rate by 0.04 percent, but this effect is not statistically significant. The lack of a significant crowd-out effect, coupled with the presence of a significant crowd-in effect, is suggestive of

\footnotetext{
${ }^{40}$ Kane (1999) analyzes annual data from 1980 to 1992.
} 
wage-sensitive college demand by natives as well as elastic college supply, particularly at the decadal frequency of the data. This hypothesis is supported empirically. The crowd-in effect is driven by natives ages 18-24, who are likely to have college demand that is more sensitive to returns than older natives. Crowd-in is also larger for natives on the margin of public school enrollment, where college slots are likely to be more elastically supplied.

I also show that the results provide evidence that immigrants do impact market prices like the relative wage. However, these effects need not be large to be consistent with the observed crowding results due to implied native sensitivity to even small market price changes, particularly wage changes.

This paper suggests that education studies on displacement effects of immigrant students on natives, by ignoring immigrant labor inflows, miss an important component of immigration that significantly affects native skill choice. Additionally, over long time horizons, I show that displacement effects appear to be small to nonexistent. Further research needs to be done, however, to compare findings in this study with those in existing crowd-out studies. Differences between the two are potentially being driven by differences in market structure (for example, the elasticity of college supply) in the long run vs. the short run, or by differences in examining all college-going natives vs. only disadvantaged natives.

Regarding the implications of this work for labor studies of immigration's effect on natives, by emphasizing a more unified framework between labor and education markets, the paper highlights an endogenous skill acquisition response by natives to immigrant inflows. This contributes to a growing literature on how such general equilibrium responses may play a role in the seemingly rapid absorption of immigrants into local markets, mitigating native wage effects of immigration, which the paper finds are negative but small.

Government policies on immigration that do not take into account how the composition of immigrant inflows is affected may have unanticipated consequences due to the resultant changes in native enrollment that this paper identifies. Moreover, distinguishing the 
degree to which individuals respond more to changes in the costs or the benefits of higher education also has direct implications for government policy. If the goal of a government intervention were to increase college enrollment rates, the paper suggests that labor market policies targeting relative wages might be more effective in the long run than education market policies adjusting costs through loans and grants.

In order to definitively make such claims, however, additional investigation is necessary to determine whether the estimated crowding effects are indeed reflective of the entire native population, or of only a subset of the native population that is not liquidityconstrained. Related to this, more work on the welfare implications of the immigrant inflows, given this native response, is also of interest and necessary before statements of optimal policy can be made (for example, Chiswick 1989, or Eberhard 2012, who finds positive native welfare implications of immigrant inflows given endogenous native human capital adjustment). Such research will be aided by additional understanding of the price and non-price mechanisms of the native response highlighted in this paper. 


\section{References}

[1] Autor, David H., Lawrence F. Katz, and Alan B. Krueger. 1998. "Computing Inequality: Have Computers Changed the Labor Market?" Quarterly Journal of Economics, 113(4): 1169-1213.

[2] Aydemir, Abdurrahman, and George J. Borjas. 2011. "Attenuation Bias in Measuring the Wage Impact of Immigration." Journal of Labor Economics, 29(1): 69-113.

[3] Bartel, Ann P. 1989. "Where Do the New Immigrants Live?" Journal of Labor Economics, 7(4): 371-391.

[4] Bertrand, Marianne, Esther Duflo, and Sendhil Mullainathan. 2004. "How Much Should We Trust Differences-in-Differences Estimates?" Quarterly Journal of Economics, 119(1): 249-275.

[5] Betts, Julian R. 1998. "Educational Crowding Out: Do Immigrants Affect the Educational Attainment of American Minorities?" In Help or Hindrance? The Economic Implications of Immigration for African-Americans, eds. D. Hamermesh and F. Bean, New York: Russell Sage Foundation.

[6] Betts, Julian R., and Robert W. Fairlie. 2003. "Does Immigration Induce 'Native Flight' from Public Schools into Private Schools?" Journal of Public Economics, 87(5-6): 987-1012.

[7] Black, Dan A., Terra G. McKinnish, and Seth G. Sanders. 2005. "Tight Labor Markets and the Demand for Education: Evidence from the Coal Boom and Bust." Industrial and Labor Relations Review, 59(1): 3-16.

[8] Borjas, George J. 1980. "The Relationship between Wages and Weekly Hours of Work: The Role of Division Bias." The Journal of Human Resources, 15(3): 409423.

[9] Borjas, George J. 2003. "The Labor Demand Curve Is Downward Sloping: Reexamining the Impact of Immigration on the Labor Market." Quarterly Journal of Economics, 118(4): 1335-1374.

[10] Borjas, George J. 2007. "Do Foreign Students Crowd Out Native Students from Graduate Programs?" In Science and the University (Science and Technology in Society), eds. P. Stephan and R. Ehrenberg, Madison: University of Wisconsin Press.

[11] Bound, John, Jeffrey Groen, Gabor Kezdi, and Sarah Turner. 2004. "Trade in University Training: Cross-State Variation in the Production and Stock of College-Educated Labor." Journal of Econometrics, 121(1-2): 143-173.

[12] Bound, John, David A. Jaeger, and Regina M. Baker. 1995. "Problems with Instrumental Variables Estimation when the Correlation Between the Instruments and the Endogenous Explanatory Variables is Weak." Journal of the American Statistical Association, 90(430): 443-450. 
[13] Bound, John, and Sarah Turner. 2007. "Cohort Crowding: How Resources Affect Collegiate Attainment." Journal of Public Economics, 91(5-6): 877-899.

[14] Boustan, Leah Platt. 2010. "Was Postwar Suburbanization 'White Flight'? Evidence from the Black Migration." Quarterly Journal of Economics, 125(1): 417-443.

[15] Cadena, Brian C. 2013. "Native Competition and Low-Skilled Immigrant Inflows." Journal of Human Resources, 48(4): 910-944.

[16] Card, David. 1990. "The Impact of the Mariel Boatlift on the Miami Labor Market." Industrial and Labor Relations Review, 43(2): 245-257.

[17] Card, David. 2001. "Immigrant Inflows, Native Outflows, and the Local Labor Market Impacts of Higher Immigration." Journal of Labor Economics, 19(1), 22-64.

[18] Card, David. 2005. "Is the New Immigration Really So Bad?" Economic Journal, 115(507): F300-F323.

[19] Card, David, and John DiNardo. 2000. "Do Immigrant Inflows Lead to Native Outflows?" American Economic Review, Papers and Proceedings, 90(2): 360-367.

[20] Card, David, and Thomas Lemieux. 2001. "Can Falling Supply Explain the Rising Return to College for Younger Men? A Cohort-Based Analysis." Quarterly Journal of Economics, 116(2): 705-746.

[21] Chiswick, Carmel U. 1989. "The Impact of Immigration on the Human Capital of Natives." Journal of Labor Economics, 7(4): 464-486.

[22] Christian, Michael. 2004. "The Responses of State Universities to Changes in the Demand for Public Higher Education, 1980-95." University of Michigan, Mimeo.

[23] Cortes, Patricia. 2008. "The Effect of Low-skilled Immigration on U.S. Prices: Evidence from CPI Data." Journal of Political Economy, 116(3): 381-422.

[24] Cortes, Patricia, and Jose Tessada. 2011. "Low-skilled Immigration and the Labor Supply of Highly Skilled Women." American Economic Journal: Applied Economics, 3(3): 88-123.

[25] Cragg, John G., and Stephen G. Donald. 1993. "Testing Identifiability and Specification in Instrumental Variable Models." Econometric Theory, 9(2): 222-240.

[26] Dai, Tiantian, Xiangbo Liu, and Biancen Xie. 2013. "The Impact of Immigrants on Host Country Crime." Economics Letters, 119(2): 157-161.

[27] Denisova, Anastasiya. 2013. "Immigration and the Educational Choices of Nativeborn Workers: the Role of Income." Georgetown University, Mimeo.

[28] Dickens, William T. 1990. "Error Components in Grouped Data: Is It Ever Worth Weighting?" The Review of Economics and Statistics, 72(2): 328-333.

[29] DiNardo, John E., and Jorn-Steffen Pischke. 1997. "The Returns to Computer Use Revisited: Have Pencils Changed the Wage Structure Too?" Quarterly Journal of Economics, 112(1): 291-303. 
[30] Dynarski, Susan M. 2003. "Does Aid Matter? Measuring the Effects of Student Aid on College Attendance and Completion." American Economic Review, 93(1): 279-288.

[31] Eberhard, Juan. 2012. "Immigration, Human Capital and the Welfare of Natives." University of Southern California Marshall School of Business, Mimeo.

[32] Fortin, Nicole M. 2006. "Higher-Education Policies and the College Wage Premium." American Economic Review, 96(4): 959-987.

[33] Genc, Serife. 2012. "Immigration in Canada: A General Equilibrium Analysis." University of Pittsburgh, Mimeo.

[34] Gould, Eric D., Victor Lavy, and M. Daniele Paserman. 2009. "Does Immigration Affect the Long-Term Educational Outcomes of Natives? Quasi-Experimental Evidence." Economic Journal, 119(540): 1243-1269.

[35] Hanson, Gordon H. 2006. "Illegal Migration from Mexico to the United States." Journal of Economic Literature, 44(4): 869-924.

[36] Heckman, James J., and Jeffrey A. Smith. 1999. "The Pre-Program Earnings Dip and the Determinants of Participation in a Social Program: Implications for Simple Program Evaluation Strategies." Economic Journal, 109(457): 313-348.

[37] Hoxby, Caroline M. 1998. "Do Immigrants Crowd Disadvantaged American Natives Out of Higher Education?" In Help or Hindrance? The Economic Implications of Immigration for African-Americans, eds. D. Hamermesh and F. Bean, New York: Russell Sage Foundation.

[38] Hunt, Jennifer. 2012. "The Impact of Immigration on the Educational Attainment of Natives." NBER Working Paper no. 18047.

[39] Imbens, Guido W., and Joshua D. Angrist 1994. "Identification and Estimation of Local Average Treatment Effects." Econometrica, 62(2): 467-475.

[40] Jackson, Osborne. 2010. "Educational Quality, Asymmetric Information, and SelfSelection in High-Skilled Migration." University of Michigan, Mimeo.

[41] Jaeger, David A. 1997. "Reconciling the Old and New Census Bureau Education Questions: Recommendations for Researchers." Journal of Business 86 Economic Statistics, 15(3): 300-309.

[42] Johnson, George E. 1997. "Changes in Earnings Inequality: The Role of Demand Shifts." Journal of Economic Perspectives, 11(2): 41-54.

[43] Kane, Thomas J. 1999. The Price of Admission: Rethinking How Americans Pay for College. Washington, D.C.: Brookings Institution Press.

[44] Katz, Lawrence F., and Kevin M. Murphy. 1992. "Changes in Relative Wages, 19631987: Supply and Demand Factors." Quarterly Journal of Economics, 107(1): 35-78. 
[45] Kleibergen, Frank, and Richard Paap. 2006. "Generalized Reduced Rank Tests Using the Singular Value Decomposition." Journal of Econometrics, 133(1): 97-126.

[46] Krueger, Alan B. 1993. "How Computers Have Changed the Wage Structure: Evidence from Micro Data, 1984-1989." Quarterly Journal of Economics, 108(1): 33-60.

[47] Leamer, Edward E. 1995. "The Heckscher-Ohlin Model in Theory and Practice." Princeton Studies in International Finance Working Paper no. 77.

[48] Lewis, Ethan. 2011. "Immigration, Skill Mix, and Capital-Skill Complementarity." Quarterly Journal of Economics, 126(2): 1029-1069.

[49] McHenry, Peter. 2015. "Immigration and the Human Capital of Natives." Journal of Human Resources, 50(1): 34-71.

[50] Moretti, Enrico. 2004. "Estimating the Social Return to Higher Education: Evidence from Longitudinal and Repeated Cross-Sectional Data." Journal of Econometrics, 121(1-2): 175-212.

[51] Munshi, Kaivan. 2003. "Networks in the Modern Economy: Mexican Migrants in the U. S. Labor Market." Quarterly Journal of Economics, 118(2): 549-599.

[52] Neumark, David, and William Wascher. 1995. "Minimum Wage Effects on Employment and School Enrollment." Journal of Business 8 Economic Statistics, 13(2): $199-206$.

[53] Ortega, Francesc, and Giovanni Peri. 2009. "The Causes and Effects of International Migrations: Evidence from OECD Countries 1980-2005." NBER Working Paper no. 14833 .

[54] Ottaviano, Gianmarco I.P., and Giovanni Peri. 2012. "Rethinking the Effects of Immigration on Wages." Journal of the European Economic Association, 10(1): 152-197.

[55] Peri, Giovanni, and Chad Sparber. 2009. "Task Specialization, Immigration, and Wages." American Economic Journal: Applied Economics, 1(3): 135-169.

[56] Roed, Marianne, and Pal Schone. 2012. "The Impact of Immigration on Investments in Vocational Skills." Institute for Social Research, Mimeo.

[57] Ruggles, Steven, Matthew Sobek, Trent Alexander, Catherine A. Fitch, Ronald Goeken, Patricia Kelly Hall, Miriam King, and Chad Ronnander. 2009. Integrated Public Use Microdata Series: Version 4.0 [Machine-readable database]. Minneapolis: University of Minnesota.

[58] Stock, James H., and Motohiro Yogo. 2005. "Testing for Weak Instruments in Linear IV Regression." Identification and Inference for Econometric Models: Essays in Honor of Thomas J. Rothenberg. Eds. Donald W.K. Andrews and James H. Stock, Cambridge: Cambridge University Press, ch.5.

[59] Wozniak, Abigail, and Thomas J. Murray. 2012. "Timing is Everything: Short-run Population Impacts of Immigration in U.S. Cities." Journal of Urban Economics, $72(1): 60-78$. 
Figure 1a: Inflow of Relatively Unskilled Immigrant Labor
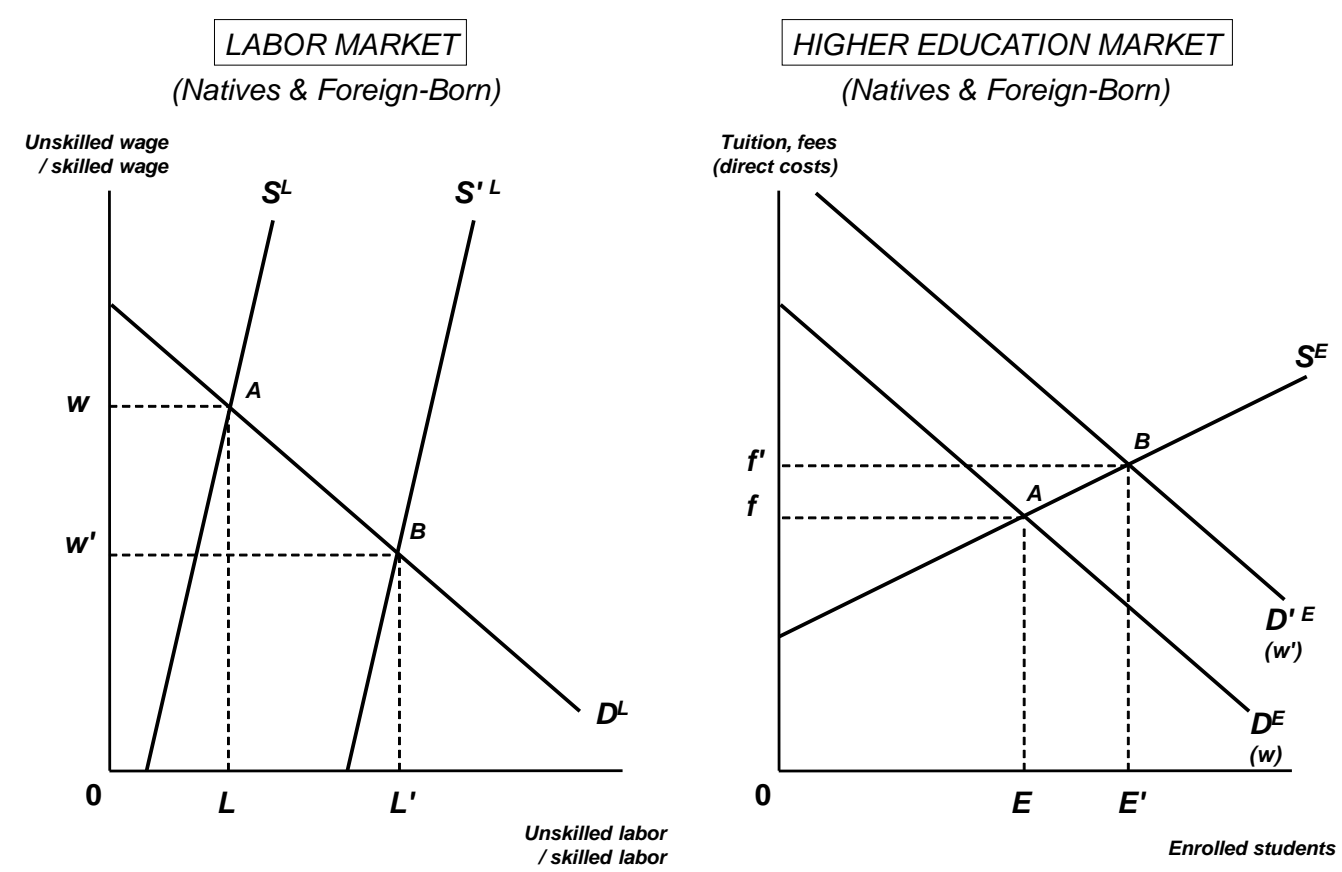

\section{NATIVE DEMAND FOR HIGHER EDUCATION}

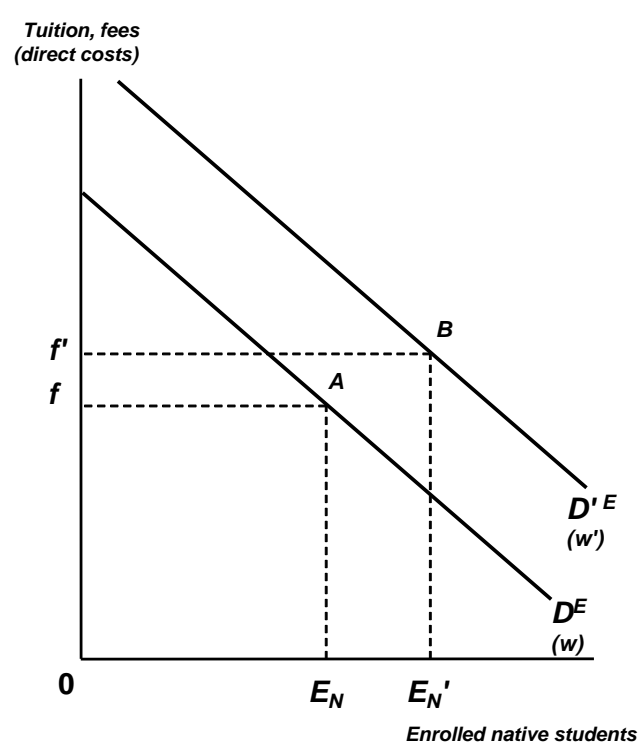

Source: Author's illustration. 
Figure 1b: Inflow of Immigrant Students
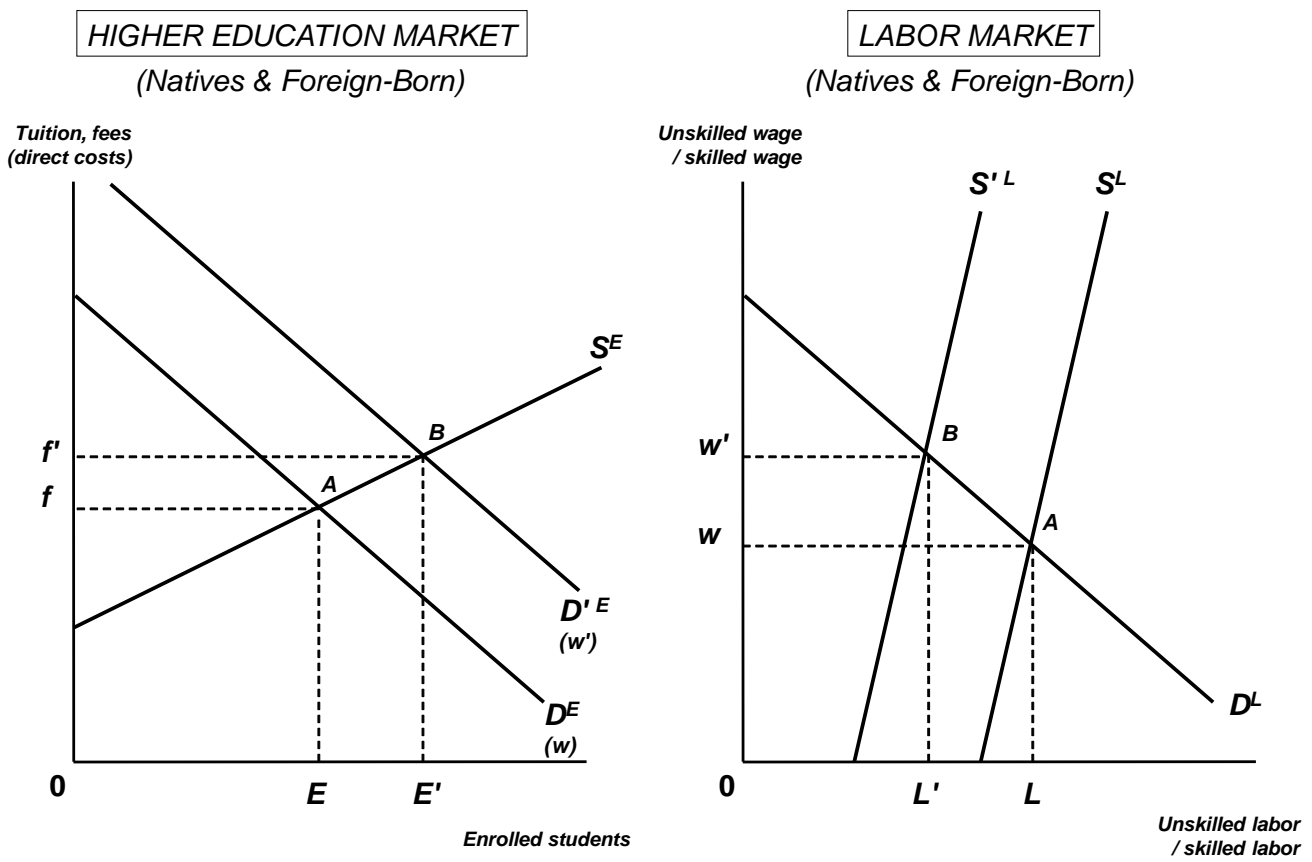

NATIVE DEMAND FOR HIGHER EDUCATION

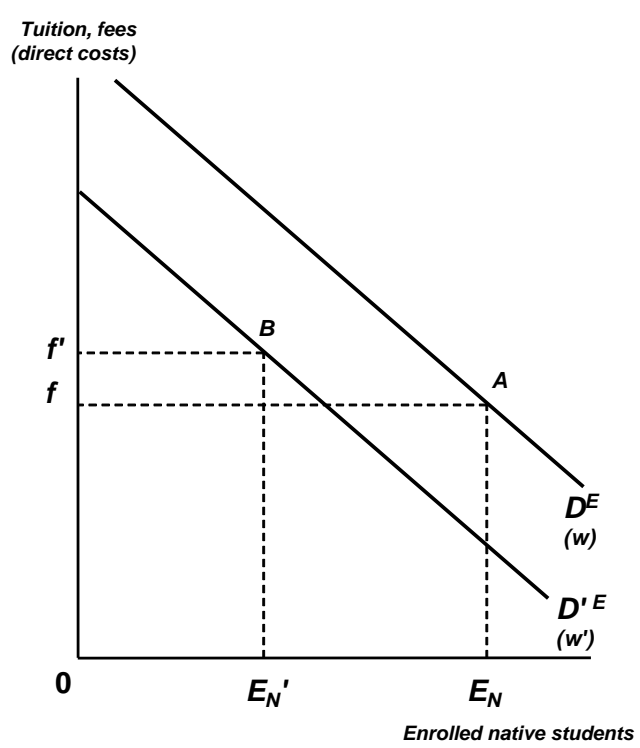

Source: Author's illustration. 
Figure 2: Relative Skilled Wage and Relative Supply of Skill

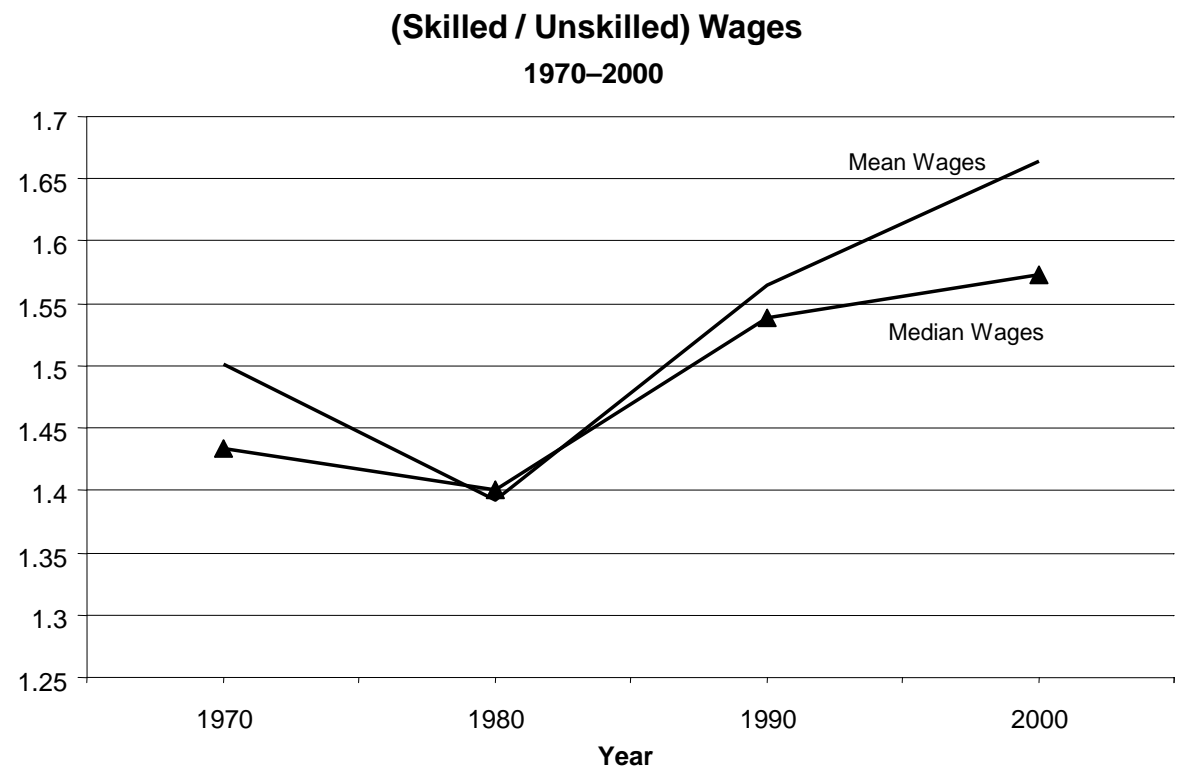

(Skilled / Unskilled) Labor Force Ratio

1970-2000

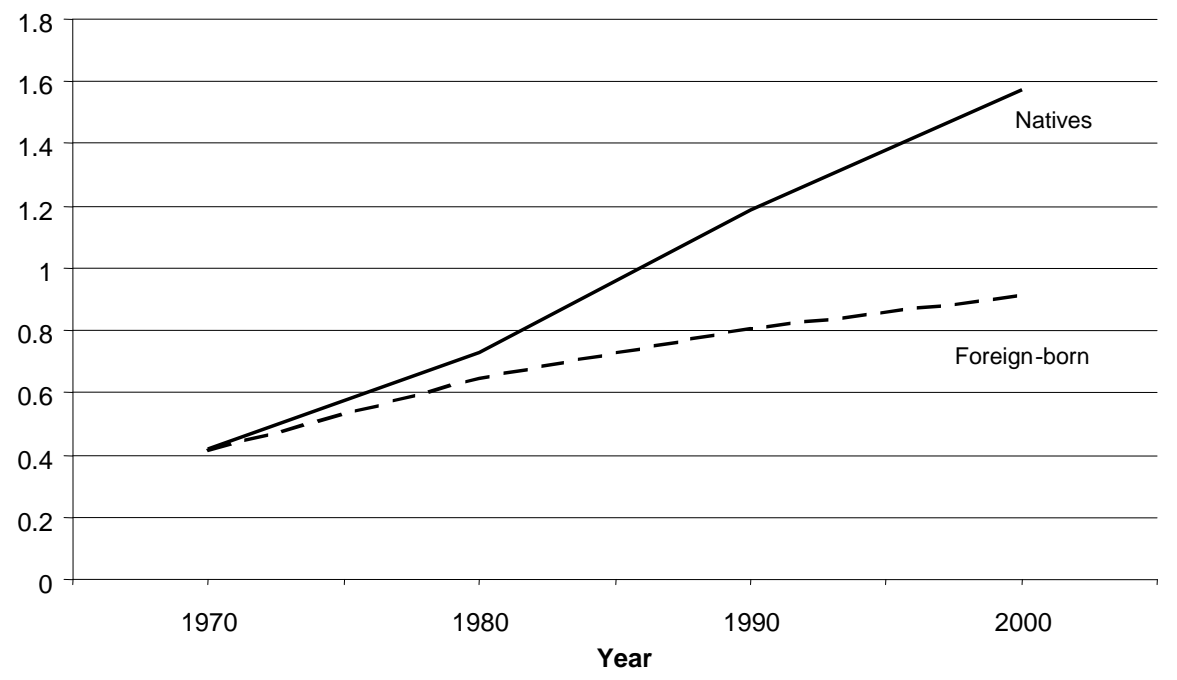

Source: U.S. Census 1970-2000 and author's calculations. To be nationally representative, trends in top and bottom panel are constructed weighting individual observations with census person weights. Top panel: wages are estimated by dividing wage/salary income (in constant 1995 USD using Bureau of Labor Statistics Consumer Price Index for All Urban Consumers (CPI-U)) by hours worked last week (1970) or usual hours worked per week (1980-2000). Sample is restricted to employed 18-64 year-old individuals with non-missing, non-zero earnings and hours, and who are neither in school nor living in group quarters. 


\section{Figure 3: Trends in U.S. College Enrollment by Group}
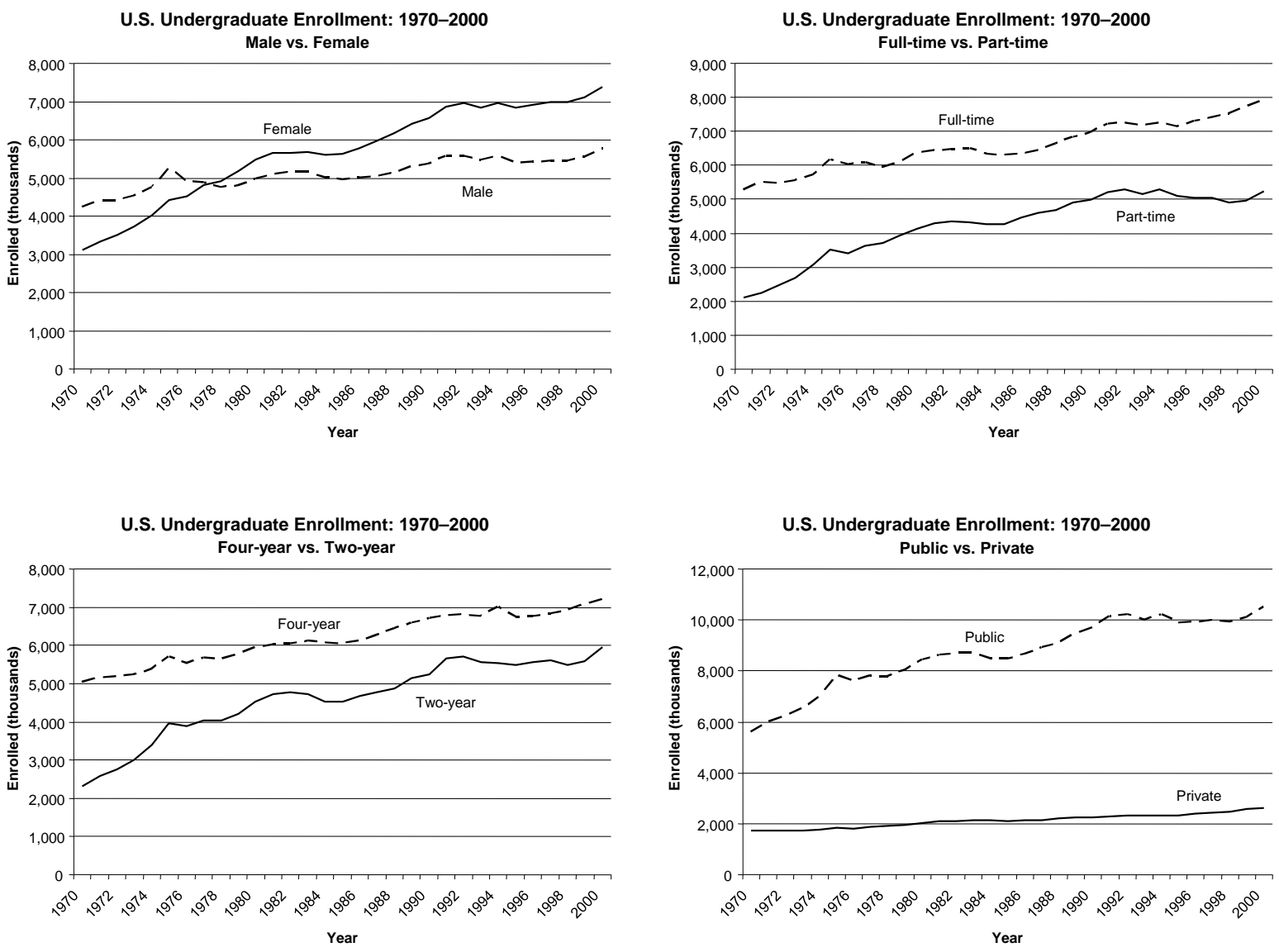

Source: U.S. Department of Education, National Center for Education Statistics (NCES), Digest of Education Statistics, $200 \%$. 
Figure 4: Geographic Variation of Predicted Immigrant Inflows 1970-2000

(a) $\Delta \ln [$ Immigrants (unskilled/skilled), labor $]$

(b) $\Delta \ln [$ Immigrants, students]
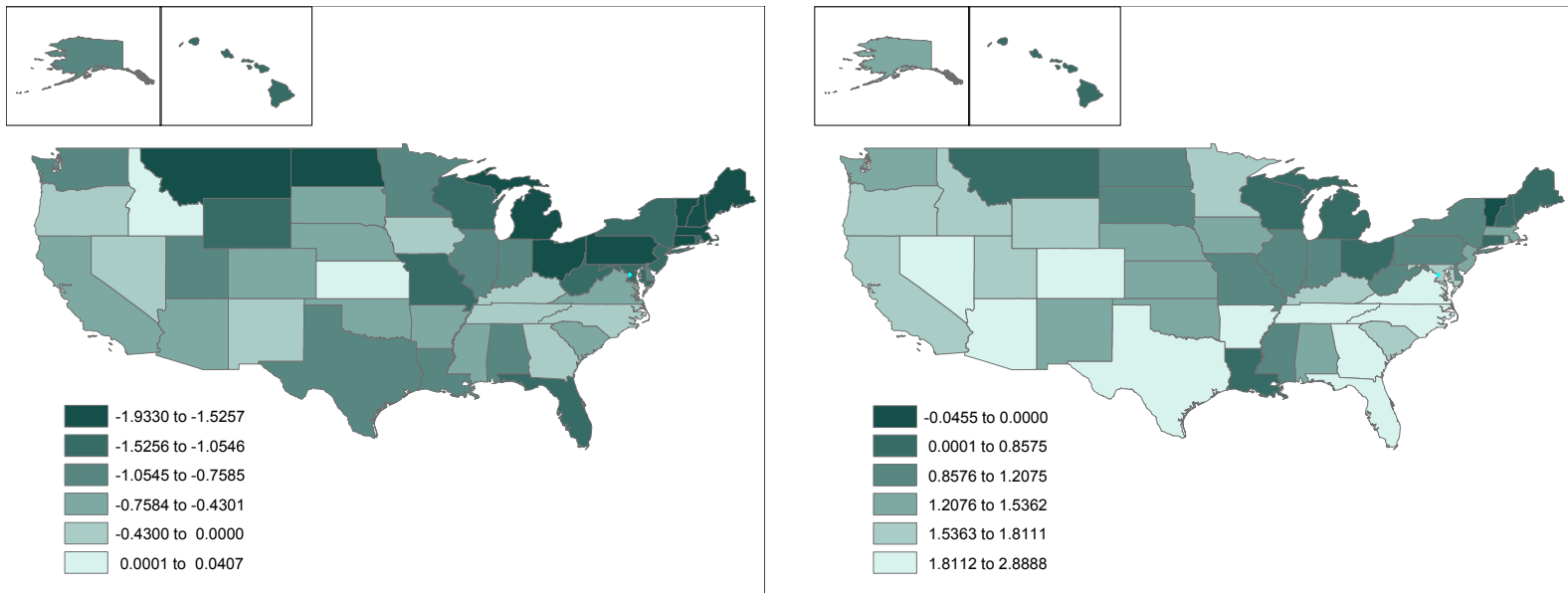

(c) $\rho$ labor,students

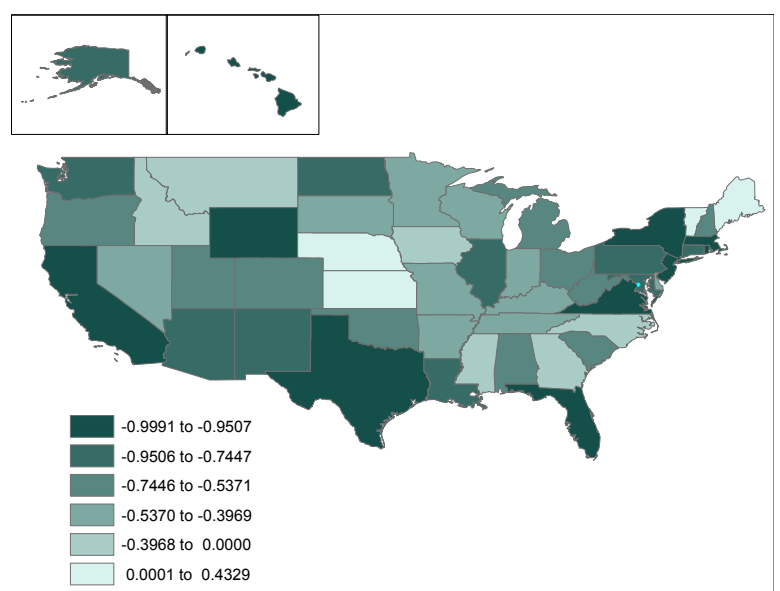

Source: U.S. Census 1970-2000 and author's calculations. Immigrant inflows are predicted, not actual, as described in text. In top two figures, differences shown for each state are between 2000 and 1970 values of the variable (that is $\Delta \equiv \Delta_{2000-1970}$ ). In bottom figure, correlations shown for each state, $\rho_{\text {labor,students, }}$, are between $\ln [\operatorname{Immigrants}$ (unskilled/skilled), labor] and $\ln$ [Immigrants, students], over all years $1970-2000$. 
Table 1: Estimating Immigrant College Demand in 1960, Marginal Effects Dependent Variable: College-Enrolled (0/1)

\begin{tabular}{|c|c|c|c|}
\hline & $\begin{array}{c}\text { Logit } \\
\text { [MLE] } \\
(1)\end{array}$ & $\begin{array}{c}\text { LPM } \\
\text { [OLS] } \\
(2)\end{array}$ & $\begin{array}{c}\text { Logit } \\
{[\mathrm{MLE}]} \\
(3)\end{array}$ \\
\hline Age & $\begin{array}{c}0.001 \\
(0.001)\end{array}$ & $\begin{array}{c}-0.013 \\
(0.000)^{* * *}\end{array}$ & $\begin{array}{c}-0.003 \\
(0.000)^{* * *}\end{array}$ \\
\hline $\mathrm{Age}^{2}$ & $\begin{array}{c}-0.000 \\
(0.000)^{* * *}\end{array}$ & $\begin{array}{c}0.000 \\
(0.000)^{* * *}\end{array}$ & \\
\hline Female & $\begin{array}{c}-0.013 \\
(0.001)^{* * *}\end{array}$ & $\begin{array}{c}-0.011 \\
(0.001)^{* * *}\end{array}$ & \\
\hline Black non-Hispanic & $\begin{array}{l}-0.001 \\
(0.004)\end{array}$ & $\begin{array}{l}-0.003 \\
(0.006)\end{array}$ & \\
\hline Asian non-Hispanic & $\begin{array}{l}-0.002 \\
(0.003)\end{array}$ & $\begin{array}{c}-0.013 \\
(0.005)^{* *}\end{array}$ & \\
\hline Hispanic & $\begin{array}{l}-0.008 \\
(0.005)\end{array}$ & $\begin{array}{c}-0.014 \\
(0.005)^{* * *}\end{array}$ & \\
\hline $\begin{array}{l}\text { Other (excl. white } \\
\text { non-Hispanic) }\end{array}$ & $\begin{array}{l}-0.001 \\
(0.004)\end{array}$ & $\begin{array}{c}0.031 \\
(0.008)^{* * *}\end{array}$ & \\
\hline Constant & $\begin{array}{c}0.002 \\
(0.013)\end{array}$ & $\begin{array}{c}0.320 \\
(0.005)^{* * *}\end{array}$ & $\begin{array}{c}0.037 \\
(0.002)^{* * *}\end{array}$ \\
\hline Source country fixed effects & Yes & Yes & No \\
\hline Observations & 58,578 & 59,084 & 59,084 \\
\hline Log likelihood & -1917.33 & & -2265.20 \\
\hline (Pseudo) $R^{2}$ & 0.46 & 0.10 & 0.37 \\
\hline \% Correct, enrolled=1 (1960) & 0.94 & 0.99 & 0.95 \\
\hline$\%$ Correct, enrolled $=0(1960)$ & 0.88 & 0.67 & 0.85 \\
\hline$\%$ Correct, enrolled $=1(1970-2000)$ & 0.69 & 0.84 & 0.73 \\
\hline \% Correct, enrolled $=0$ (1970-2000) & 0.73 & 0.47 & 0.68 \\
\hline
\end{tabular}

$* p<0.10,{ }^{* *} p<0.05, * * * p<0.01$

Notes: All specifications are estimated in 1960, using U.S. Census data, and weight individual observations using census person weights. Specifications (1) and (2) also include source country dummies (not reported). "White Non-Hispanic" is the omitted racial category. Average marginal effects are reported for all specifications, and for the logistic models are calculated at the sample average rate of college enrollment in 1960, $\hat{\beta}^{*} \bar{y} *(1-\bar{y})$. "\% Correct" is the proportion of accurate insample (1960) or out-of-sample (1970-2000) predictions for enrolled or not-enrolled individuals. An individual is predicted to be enrolled if $\hat{y}>\bar{y}$, and not enrolled if $\hat{y} \leq \bar{y}$. Standard errors in parentheses. 


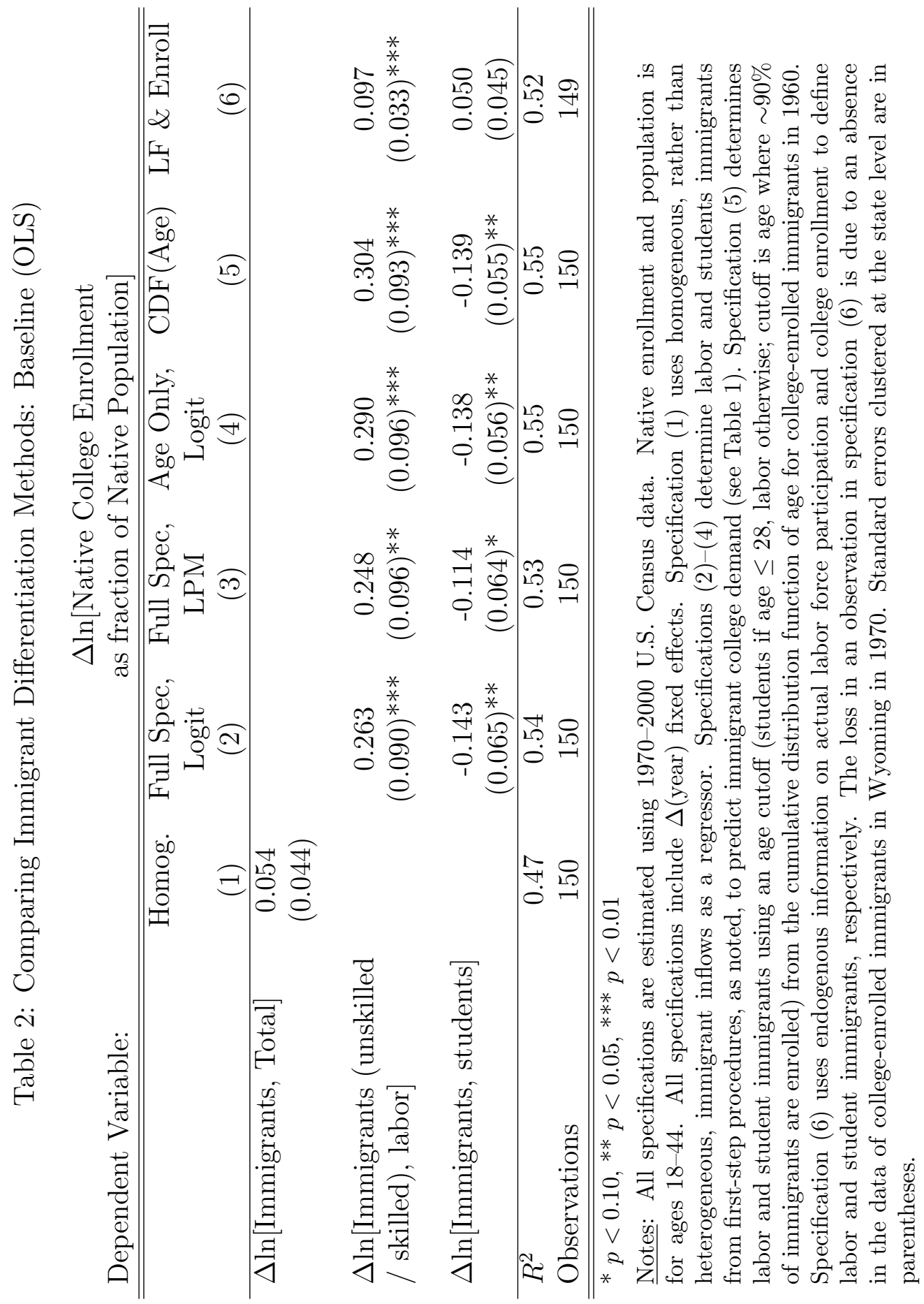




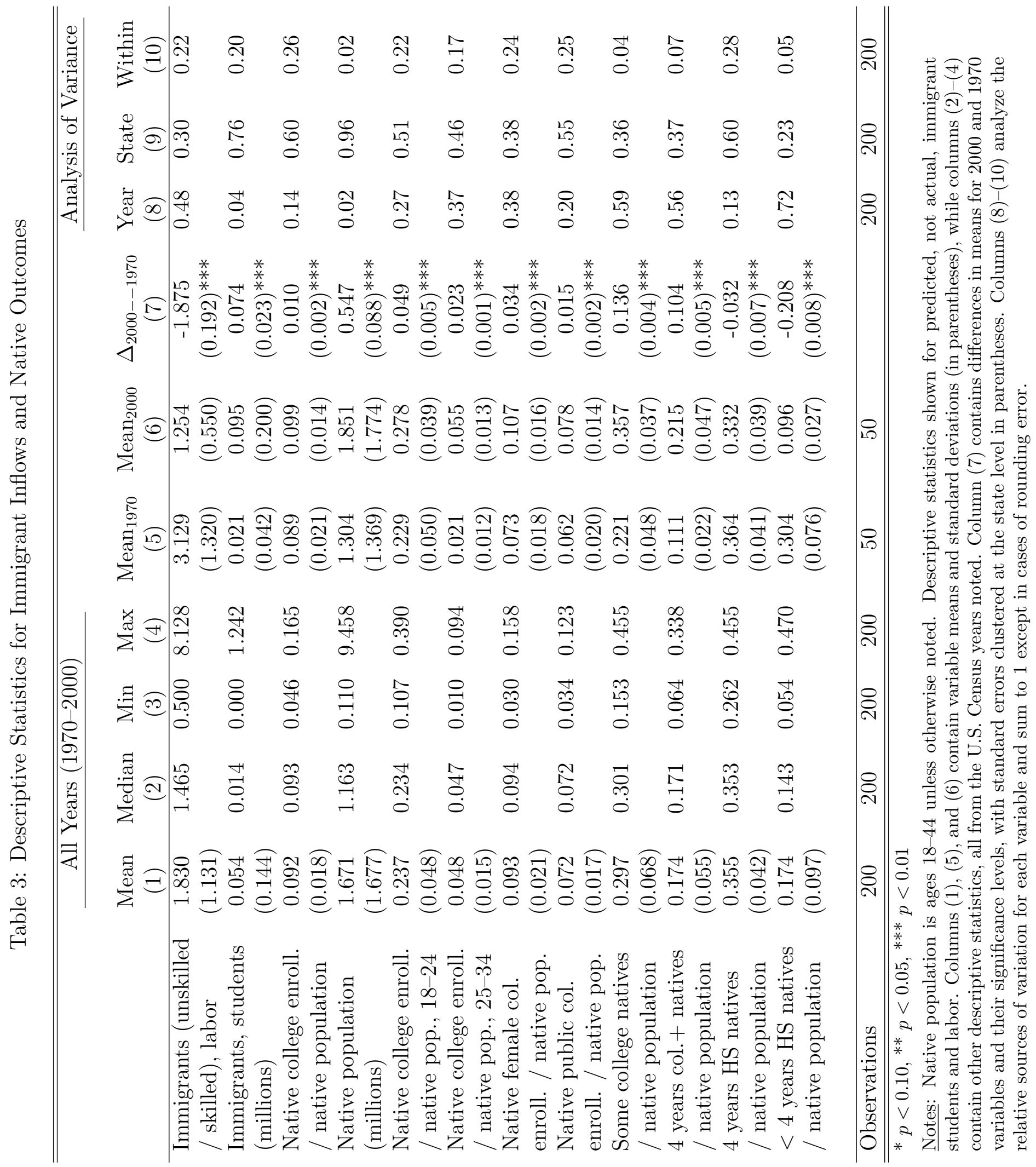


Table 4: The Impact of Immigrant Enclaves on Immigrant Inflows, First Stage (OLS)

$\Delta \ln [$ Immigrants (unskilled $\Delta \ln [$ Immigrants,

Dependent Variable:

/ skilled), labor] students]

\begin{tabular}{lcc}
\hline \hline & $(1)$ & $(2)$ \\
\hline$[(1960$ immigrant share $) \times$ & 0.164 & 0.263 \\
$\Delta($ immigrants, labor, unskilled $)]$ & $(0.048)^{* * *}$ & $(0.063)^{* * *}$ \\
{$[(1960$ immigrant share $) \times$} & -0.250 & 0.042 \\
$\Delta($ immigrants, labor, skilled $)]$ & $(0.101)^{* *}$ & $(0.162)$ \\
{$[(1960$ immigrant share $) \times$} & -0.128 & -0.514 \\
$\Delta($ immigrants, students $)]$ & $(0.105)$ & $(0.200)^{* *}$ \\
{$[(1960$ immigrant share $) \times$} & -0.012 & -0.020 \\
$\Delta($ immigrants, labor, unskilled $)]^{2}$ & $(0.003)^{* * *}$ & $(0.004)^{* * *}$ \\
{$[(1960$ immigrant share $) \times$} & 0.022 & -0.026 \\
$\Delta($ immigrants, labor, skilled $)]^{2}$ & $(0.013)^{*}$ & $(0.021)$ \\
{$[(1960$ immigrant share $) \times$} & 0.068 & 0.165 \\
$\Delta($ immigrants, students $)]^{2}$ & $(0.022)^{* * *}$ & $(0.044)^{* * *}$ \\
\hline$R^{2}$ & 0.53 & 0.51 \\
Observations & 150 & 150 \\
F-stat on enclaves=0 & & \\
p-value & 37.57 & 49.76 \\
\hline \hline$* 2<0.0, * * p<0.05, * * p<0.01$ & 0.00 \\
\hline
\end{tabular}

${ }^{*} p<0.10,{ }^{* *} p<0.05,{ }^{* * *} p<0.01$

Notes: Regressors are constructed from individual-level 1960 U.S. Census data and aggregated to the state-year level. All immigrant inflows are predicted, not actual, as described in text (section 4). For source country $h$, state $j$, and year $t$, the general form of the regressor is $\sum_{h}\left(\right.$ Immigrants $\left._{h j, 1960}\right) \times \Delta\left(\right.$ Immigrants $\left.s_{h, 1960}\right) \times$ Imrant_Type $)_{h t}$. The Immigrant_Type stocks utilized are: (1) unskilled immigrant labor, (2) skilled immigrant labor, and (3) immigrant students. Both specifications include $\Delta$ (year) fixed effects. All coefficients and standard errors are multiplied by 100,000 . Reported coefficients are thus the marginal effects of increases in the predicted (via 1960 historical shares) flows of 100,000 immigrants on the flows of immigrant labor and students, as specified by the dependent variable. Standard errors clustered at the state level are in parentheses. 


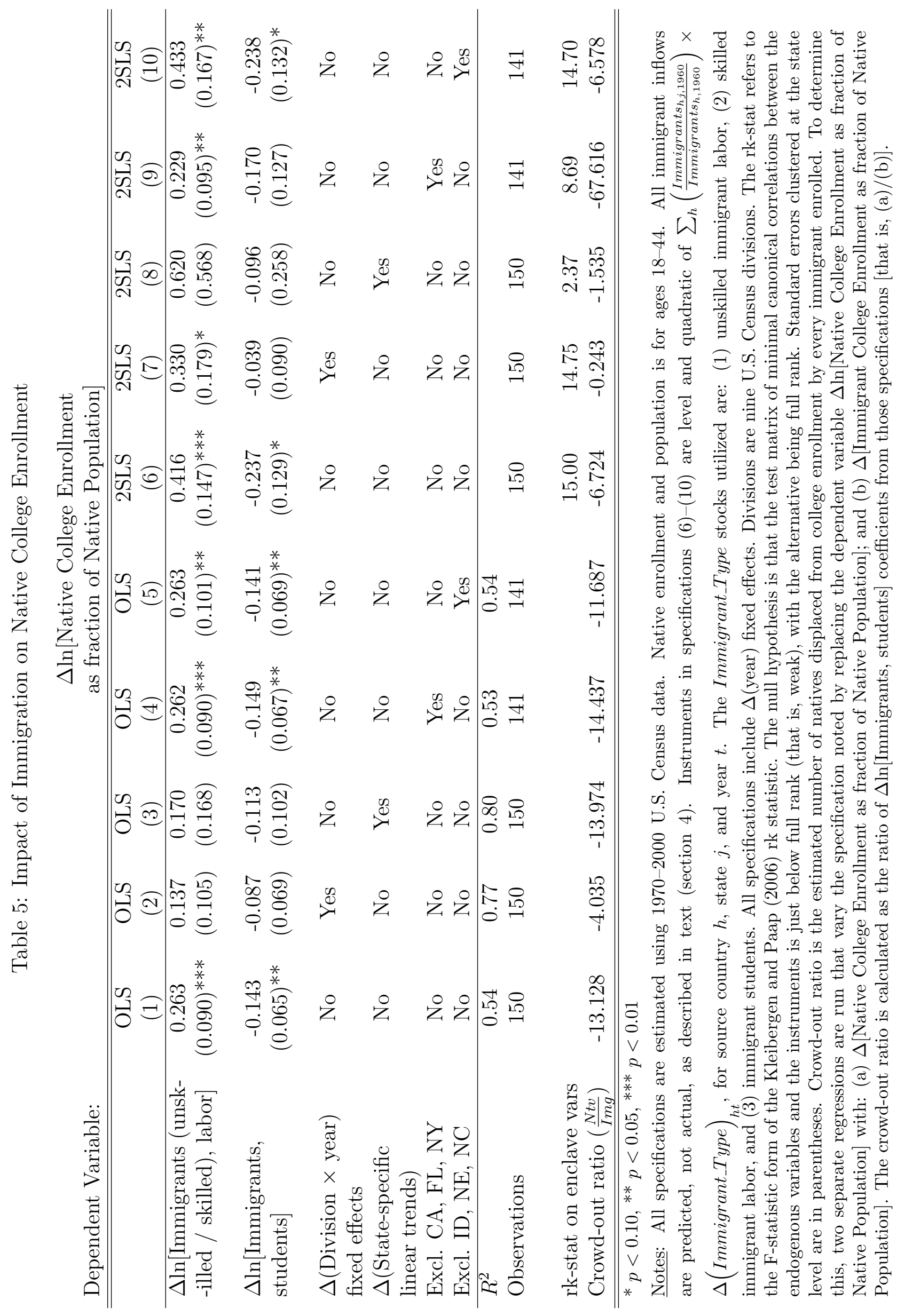


Table 6: Estimates Using Relatively Unskilled Total Labor

\begin{tabular}{lcccc} 
& \multicolumn{4}{c}{$\Delta \ln [$ Native College Enrollment } \\
Dependent Variable: & OLS & OLS & 2SLS & 2SLS \\
& $(1)$ & $(2)$ & $(3)$ & $(4)$ \\
\hline \hline & -0.067 & -0.048 & -0.051 & 0.087 \\
& $(0.053)$ & $(0.051)$ & $(0.070)$ & $(0.062)$ \\
& & & & \\
& -0.372 & -0.327 & -0.382 & -0.187 \\
$\Delta \ln [$ Immigrants, students] & $(0.143)^{* *}$ & $(0.137)^{* *}$ & $(0.231)$ & $(0.190)$ \\
$/$ skilled), labor] & No & Yes & No & Yes \\
$\begin{array}{lcccc}\Delta(\text { Division } \times \text { year) fixed effects } \\
R^{2}\end{array}$ & 0.50 & 0.77 & & \\
$\begin{array}{l}\text { Observations } \\
\text { rk-stat on enclave vars }\end{array}$ & 150 & 150 & 150 & 150 \\
\hline \hline
\end{tabular}

${ }^{*} p<0.10,{ }^{* *} p<0.05,{ }^{* * *} p<0.01$

Notes: All specifications are estimated using 1970-2000 U.S. Census data. Native enrollment and population is for ages 18-44. All immigrant inflows are predicted, not actual, as described in text (section 4). $\Delta \ln [$ Total (unskilled/skilled), labor] is composed of predicted immigrant labor inflows and native population ages 45-64. Instruments in specifications (3) and (4) are level and quadratic of $\sum_{h}\left(\frac{\text { Immigrants } s_{h j, 1960}}{\text { Immigrants } s_{h, 1960}}\right) \times \Delta(\text { Immigrant_Type })_{h t}$, for source country $h$, state $j$, and year $t$. The Immigrant_Type stocks utilized are: (1) unskilled immigrant labor, (2) skilled immigrant labor, and (3) immigrant students. All specifications include $\Delta$ (year) fixed effects. Divisions are nine U.S. Census divisions. The rk-stat refers to the Fstatistic form of the Kleibergen and Paap (2006) rk statistic. The null hypothesis is that the test matrix of minimal canonical correlations between the endogenous variables and the instruments is just below full rank (that is, weak), with the alternative being full rank. Standard errors clustered at the state level are in parentheses. 


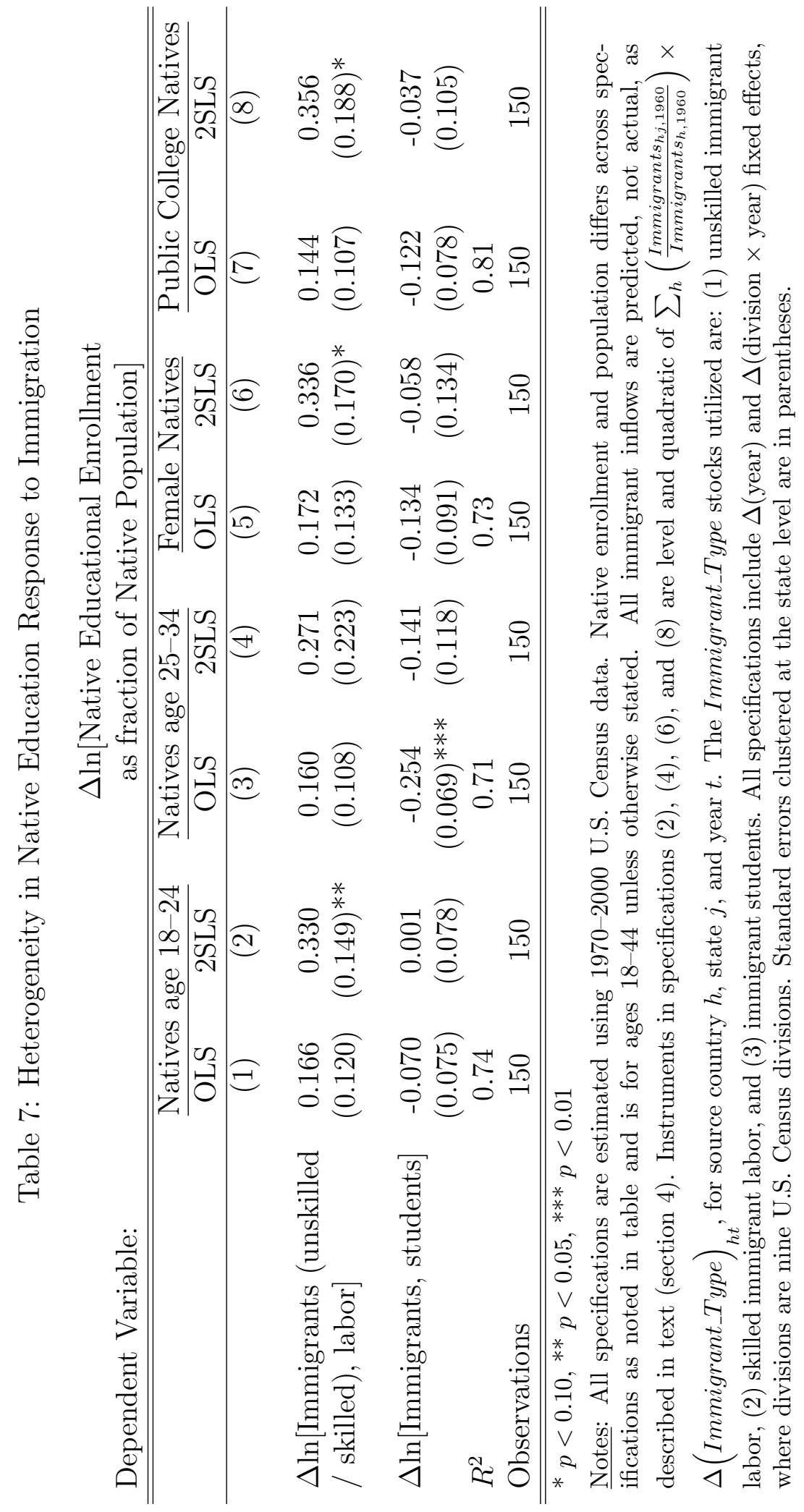




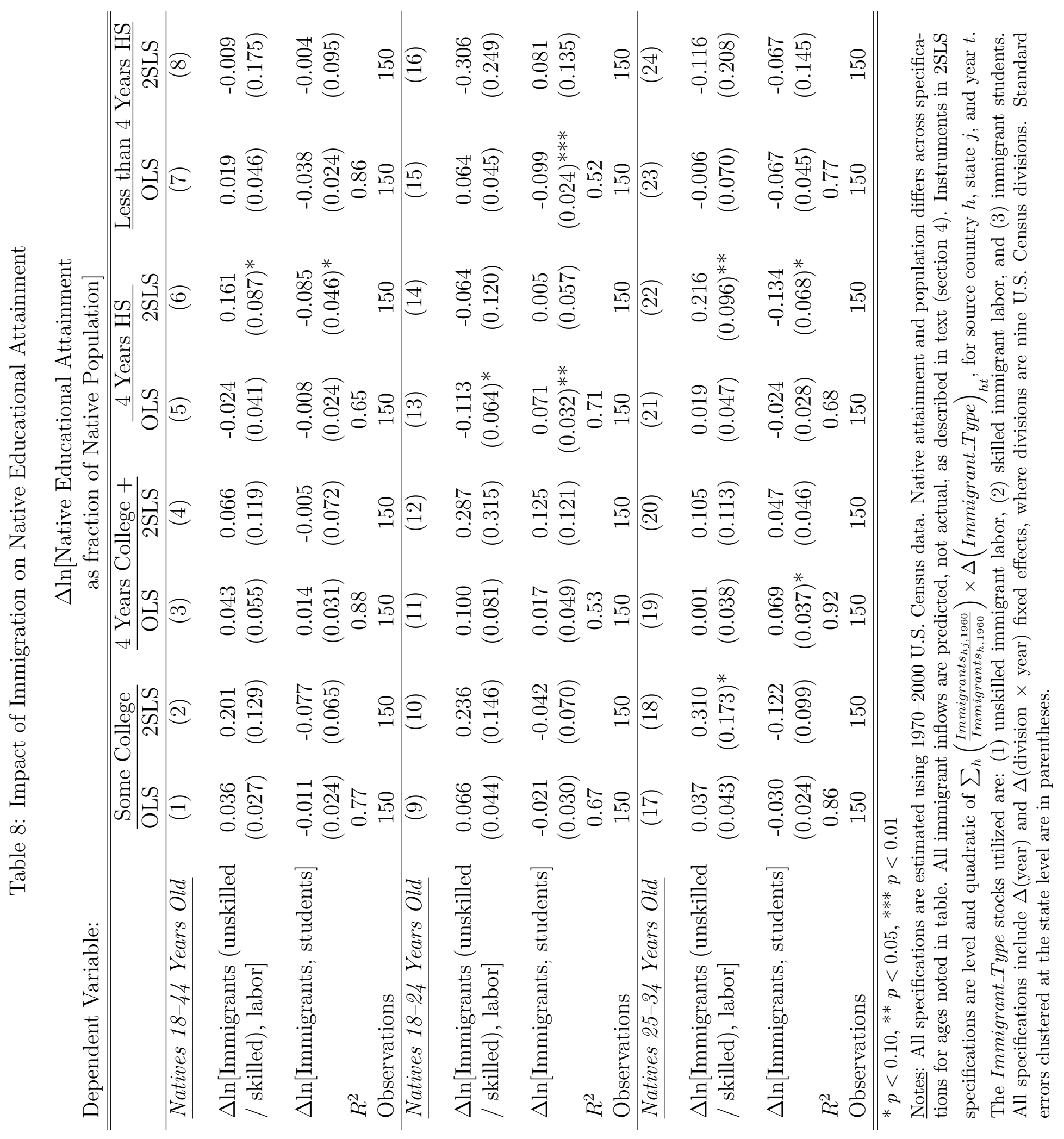




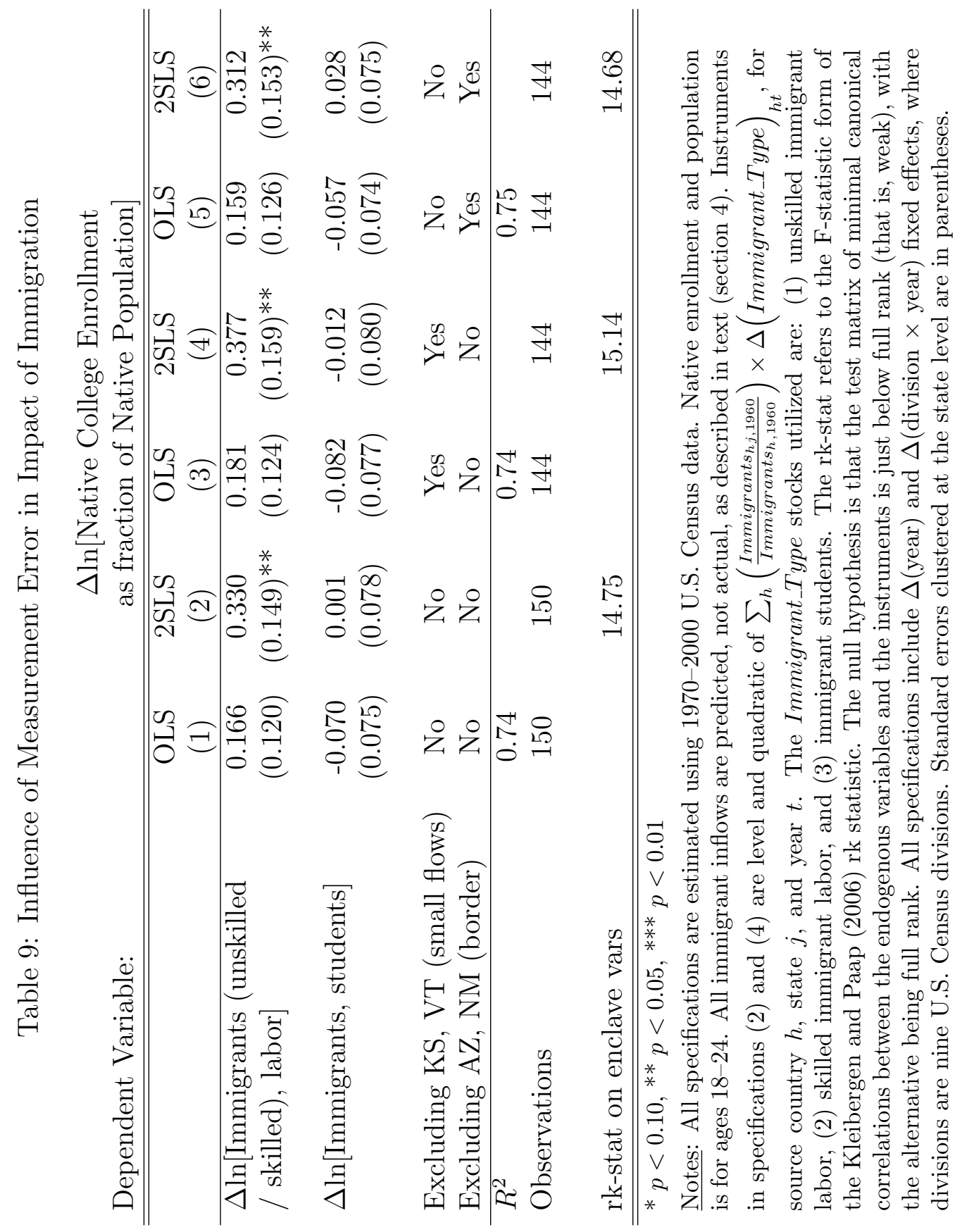




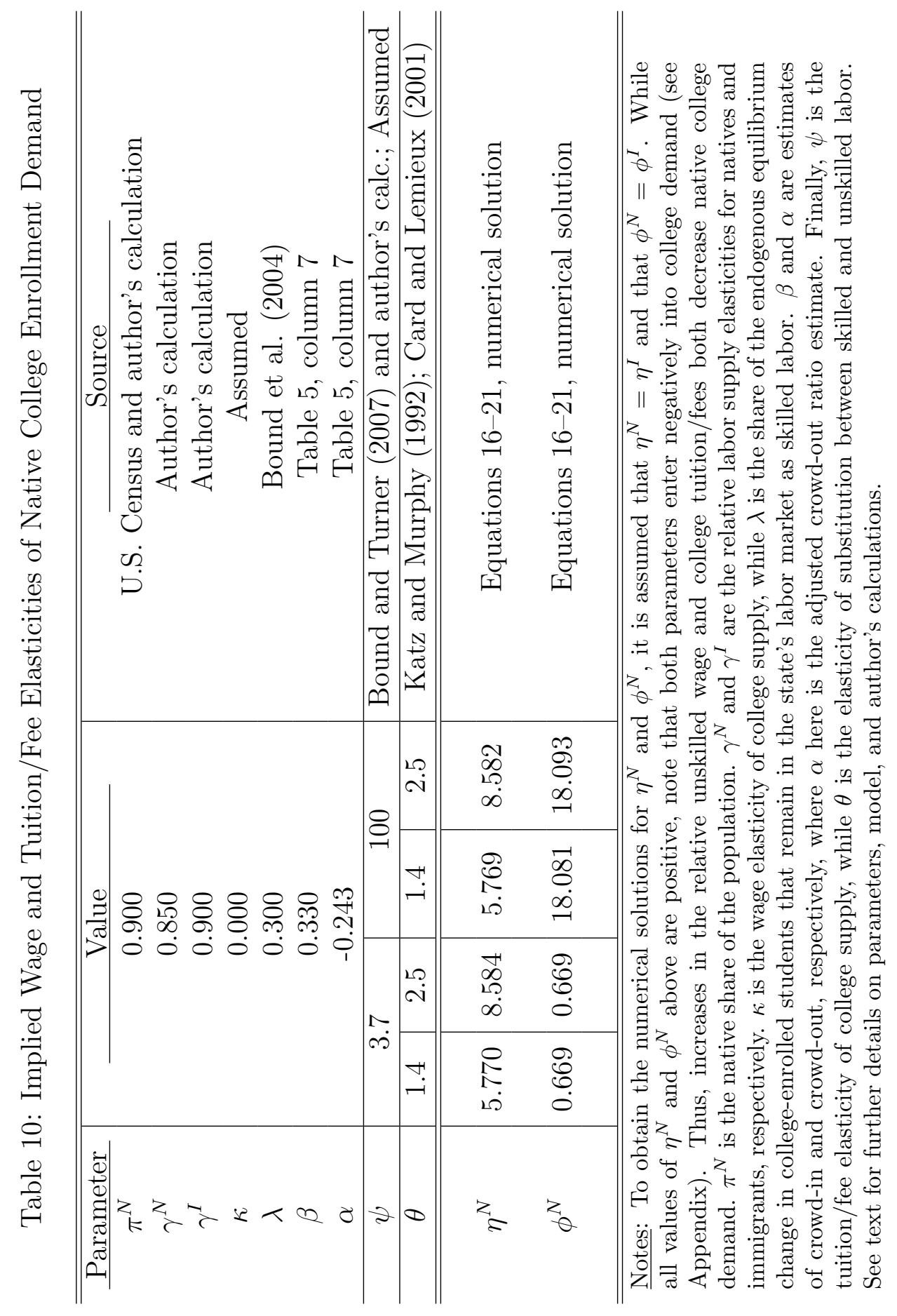




\section{Appendix: Theory}

\section{A Model of Immigration and Native College Enrollment}

\section{Assumptions}

I present here an algebraic version of the conceptual model in the paper in the spirit of Bound et al. (2004). ${ }^{41}$ Several of the model assumptions are already presented in the paper, so only additional details are now provided.

It is assumed that all input and product markets are competitive. Production of enrollment slots by college institutions maximizing their net benefit of student enrollment is accomplished using constant returns to scale technologies and non-labor inputs (for example, land, capital) ${ }^{42}$ where student tuition/fees are received for each slot. ${ }^{43}$ Meanwhile, on the enrollment demand side, natives and immigrants of some latent ability decide whether to enroll in order to acquire skill to maximize their utility, concave in consumption. Consumption itself is a function of either skilled wages net of college tuition/fees or else unskilled wages. $^{44}$

In the labor market, regarding labor supply, all individuals are in the labor force if they are not students acquiring skill. ${ }^{45}$ On the labor demand side, with constant returns to scale technologies, firms produce a composite, nontraded good using both skilled and unskilled labor. The restriction to a single sector with a nontraded commodity simplifies the model considerably to focus on areas of interest for this paper, as consumer output demand reduces to individuals maximizing their utility over consumption of the composite good by maximizing their discounted stream of net wages. Additionally, cast in the framework of a basic Heckscher-Ohlin model, the existence of a nontraded commodity allows the wages of both skilled and unskilled workers to be determined locally, to the extent that labor is somewhat immobile across states (Leamer 1995; Cortes 2008).

\section{Setup}

Let $N \equiv$ natives (as before), $I \equiv$ immigrants, $U \equiv$ unskilled, $S \equiv$ skilled, and $L_{k}=N_{k}+I_{k}$ for $k=U, S$. Also, for any variable $x$, let $\dot{x} \equiv d \ln x$, the percentage change in $x$.

The higher education market for college enrollment can be described by the following equations:

\footnotetext{
${ }^{41}$ This version of the model, however, differs in a few ways from theirs, such as including an extended modeling of the college market and the incorporation of immigration into both the labor and college markets.

${ }^{42}$ I assume labor is only utilized for production of the output good. Also, because colleges are nonprofit institutions, I allow for the possibility that arguments unrelated to profit, such as campus diversity, may enter into colleges' objective functions.

${ }^{43}$ Because non-labor input costs remain in the background, they serve as college supply shifters. Additionally, while college slots are likely infinitely or nearly infinitely supplied at any given relative wage, the model does not presuppose this and allows for a more general wage relationship.

${ }^{44}$ Ability affects the psychic costs of schooling and may also affect the wage benefit, thus impacting the sensitivity of college demand to prices.

${ }^{45}$ Empirically, I focus on working-age, pre-retirement individuals in order to help support this assumption.
} 


$$
\begin{array}{cr}
\dot{d}_{E}=-\phi \dot{f}-\eta \dot{w}+\dot{\mu} & \text { [College Demand], } \\
\dot{s}_{E}=\psi \dot{f}+\kappa \dot{w}+\dot{\varphi} & \text { [College Supply], }
\end{array}
$$

where $\dot{f}$ is the percentage change in tuition/fees, while $\dot{w}=\dot{W}_{U}-\dot{W}_{S}$ is the percentage change in the relative unskilled wage. Parameters $\phi$ and $\eta$ are, respectively, tuition/fee and wage elasticities of college demand, while $\psi$ and $\kappa$ are, respectively, tuition/fee and wage elasticities of college supply. ${ }^{46}$ Both college demand and college supply aggregate across natives and immigrants. In particular, I specify total college demand (in a geographic market) to be a function of both native and immigrant college demand, such that $\dot{d}_{E}=$ $\pi^{N} \dot{d}_{E}^{N}+\pi^{I} \dot{d}_{E}^{I}$. Note that $\pi^{N} \in[0,1]$ is the native share of the total population (that is, the population across the college and labor markets), while $\pi^{I}=1-\pi^{N}$ is the analogous immigrant share. ${ }^{47}$ Combined, this also implies that $\phi=\pi^{N} \phi^{N}+\pi^{I} \phi^{I}, \eta=\pi^{N} \eta^{N}+\pi^{I} \eta^{I}$, and $\dot{\mu}=\pi^{N} \dot{\mu}^{N}+\pi^{I} \dot{\mu}^{I}$. Lastly, college demand and college supply shifters are represented by $\mu$ and $\varphi$, respectively.

The labor market for relatively unskilled labor can be described by the following equations:

$$
\begin{array}{cc}
\dot{d}_{L} \equiv \dot{L}_{U}^{d}-\dot{L}_{S}^{d}=-\theta \dot{w}+\dot{\zeta} & \text { [Labor Demand }], \\
\dot{s}_{L} \equiv \dot{L}_{U}^{s}-\dot{L}_{S}^{s}=\gamma \dot{w}+\dot{\xi} & {[\text { Labor Supply }],}
\end{array}
$$

where $\theta$ is the elasticity of substitution between skilled and unskilled labor, and $\gamma$ is the relative labor supply elasticity, representing wage sensitivity of labor supplied both within-state and between states (that is, the cross-state migration elasticity). ${ }^{48}$ Equations (9) and (10), while appearing quite general, are directly analogous to models in previous studies (for example, Borjas 2003; Card 2001). ${ }^{49}$ Both labor demand and labor supply

\footnotetext{
${ }^{46}$ Although assumed otherwise, it remains a possibility that the college supply function with respect to tuition is actually negatively sloped, due to a reduction in average costs when colleges expand (Christian 2004). Empirically, such economies of scale would reduce the magnitude of the crowd-out effects I estimate and even allow such effects to be positive.

${ }^{47}$ For college demand, inclusion of the $\pi$ population shares could follow, for instance, from a CobbDouglas production-style framework for the level of college demand $D_{E}$, where $D_{E}=D_{E}^{N, \alpha} D_{E}^{I,(1-\alpha)} \Leftrightarrow$ $\ln D_{E}=\alpha \ln D_{E}^{N}+(1-\alpha) \ln D_{E}^{I}$, and $\alpha$ is natives' share in college demand, captured by $\pi^{N}$.

${ }^{48}$ This implies that as labor becomes more mobile, $\gamma \rightarrow \infty$. Therefore, perfect labor mobility is a sufficient but not necessary condition for a perfectly elastic labor supply, consistent with Bound et al. (2004).

${ }^{49}$ For instance, I can use Card's (2001) framework for output in a competitive local market (that is, city) $c$ and occupation/skill group $j$, where $N_{j c}$ and $e_{j c}$ are city-skill-specific workers and productivity shocks, respectively. Relative labor demand in this model between skill groups $j$ and $k$ in market $c$ would be $\log \left(\frac{N_{j c}}{N_{k c}}\right)=-\sigma \log \left(\frac{w_{j c}}{w_{k c}}\right)+(\sigma-1) \log \left(\frac{e_{j c}}{e_{k c}}\right)$, where $\sigma$ is the elasticity of substitution between skills. Letting $\tilde{x}_{c}=\frac{x_{j c}}{x_{k c}} \forall x$, this can be rewritten as $\log \tilde{N}_{c}=-\sigma \log \tilde{w}_{c}+(\sigma-1) \log \tilde{e}_{c}$. Taking log differences leads to an equation that corresponds directly to equation (9) in this paper, with $\dot{d}_{L} \equiv \dot{\tilde{N}}_{c},-\theta \dot{w} \equiv-\sigma \dot{\tilde{w}}_{c}$, and $\dot{\zeta} \equiv(\sigma-1) \dot{\tilde{e}}_{c}$. A similar correspondence can be shown between, for instance, Card's (2001) representation of city-skill-specific labor supply and equation (10). Because Card (2001) actually specifies labor force
} 
aggregate across natives and immigrants. ${ }^{50}$ In particular, I specify total labor supply to be a function of both native and immigrant labor supply, such that $\dot{s}_{L}=\left(N_{U}^{s} \dot{+} I_{U}^{s}\right)-$ $\left(N_{S}^{s} \dot{+} I_{S}^{s}\right)=\left(\pi^{N} \gamma^{N}+\pi^{I} \gamma^{I}\right) \dot{w}+\pi^{N} \dot{\xi}^{N}+\pi^{I} \dot{\xi}^{I}{ }^{51}$ This implies that $\gamma=\pi^{N} \gamma^{N}+\pi^{I} \gamma^{I}$ and $\dot{\xi}=\pi^{N} \dot{\xi}^{N}+\pi^{I} \dot{\xi}^{I}$. Additionally, labor demand and labor supply shifters are represented by $\zeta$ and $\xi$, respectively.

Lastly, as discussed earlier, since enrollment determines skill, there is a functional link between changes in equilibrium enrollment in the college market and shifts in the relative supply of unskilled labor in the labor market. I specify this link as follows:

$$
\dot{\xi}=\dot{\nu}-\lambda \dot{d}_{E}^{*}
$$

where $\lambda \in[0,1]$ is the share of the endogenous equilibrium change in college-enrolled students, $\dot{d}_{E}^{*}$, who remain in the state's labor market as skilled labor, and I have assumed that $\lambda^{N}=\lambda^{I}=\lambda .^{52}$ Meanwhile, $\dot{\nu}$ represents the exogenous component of $\dot{\xi}$ - namely, labor supply shocks that originate in the labor market, unrelated to the college market (for example, labor immigration). ${ }^{53}$

\section{Equilibrium}

Equations (7)-(10) for demand and supply in the college and labor markets and equation (11) linking equilibrium changes in the college market to labor supply shifts together form an equilibrium in market prices and quantities. All analysis of interest in the paper assumes no confounding labor demand and college supply shifts, so the following equations specify the equilibrium imposing the restriction that $\dot{\zeta}=\dot{\varphi}=0$ :

$$
\begin{gathered}
\dot{f}^{*}=\Delta \dot{\mu}+(\Lambda \Delta \Gamma) \dot{\xi}, \\
\dot{w}^{*}=-\Gamma \dot{\xi}
\end{gathered}
$$

participation (that is, $\log \left(\frac{N_{j c}}{P_{j c}}\right)$, where $P_{j c}$ is city-skill-specific population), it can be shown that when specifying relative labor supply, $\log \left(\frac{N_{j c}}{N_{k c}}\right)$, both relative population, $\log \left(\frac{P_{j c}}{P_{k c}}\right)$, as well as relative shocks to labor supply from other sources, combine to correspond to the term $\dot{\xi}$ in equation (10). This aligns with this paper's intuition for $\dot{\xi}$ as originating from both demographic and non-demographic shocks.

${ }^{50}$ For labor demand, although a clear simplification, natives and immigrants of a given skill level (and, implicitly, geographic market) are assumed to be perfect substitutes. This, too, is comparable to many previous studies (for example, Borjas 2003; Card 2001)

${ }^{51}$ Like college demand, for labor supply, inclusion of the $\pi$ shares would follow from specification of the level of labor supply.

${ }^{52}$ This assumption, while not necessary, simplifies the exposition quite a bit. Also note that since equilibrium will impose that $\dot{d}_{E}^{*}=\dot{s}_{E}^{*}$, the latter could equivalently be substituted into equation (11). Although in this static model, enrollment and attainment are equivalent, in reality $\lambda$ could also partly represent the fact that the enrolled population will form a subset of the total skilled population.

${ }^{53}$ This is consistent with Fortin (2006), who, in her dual-market, supply-demand econometric model, specifies equilibrium college enrollment, relative labor supply, and (inverse) relative labor demand functions at the state-year level, with relative labor supply as a function of past enrollment rates (that is, homegrown relative labor supplies) and relative in-migration to the state. 


$$
\begin{gathered}
\dot{s}_{L}^{*}=(\theta \Gamma) \dot{\xi} \\
\dot{d}_{E}^{*}=\frac{(\psi \Delta) \dot{\mu}+(\Omega \Delta \Gamma) \dot{\nu}}{1+\lambda},
\end{gathered}
$$

where $\Delta=\left(\frac{1}{\psi+\phi}\right), \Gamma=\left(\frac{1}{\gamma+\theta}\right), \Lambda=\kappa+\eta$, and $\Omega=\eta \psi-\kappa \phi$. Note again for equations (12)-(14) that $\dot{\xi}=\dot{\nu}-\lambda \dot{d}_{E}^{*}$, with $\dot{d}_{E}^{*}$ specified in equation (15). Positive shifts in relatively unskilled labor supply, $\dot{\nu}$, decrease relative unskilled wages but increase tuition/fees, while positive shifts in college demand, $\dot{\mu}$, increase both tuition/fees and relative unskilled wages.

\section{Parameters}

I am interested in the effect of exogenous shifts in relatively unskilled immigrant labor supply $\left(\dot{\nu}^{I}\right)$ and immigrant college enrollment demand $\left(\dot{\mu}^{I}\right)$ on equilibrium native college enrollment demanded $\left(\dot{d}_{E}^{N *}\right)$. However, I do not observe the shocks $\dot{\nu}^{I}$ and $\dot{\mu}^{I}$ directly, but rather observe the equilibrium immigrant quantities $\dot{s}_{L}^{I *}$ and $\dot{d}_{E}^{I *}$, where $\dot{s}_{L}^{I} \equiv \dot{I}_{U}^{s}-\dot{I}_{S}^{s}=$ $\gamma^{I} \dot{w}+\dot{\xi}^{I}$ and $\dot{d}_{E}^{I}=-\phi^{I} \dot{f}-\eta^{I} \dot{w}+\dot{\mu}^{I}$.

\section{Crowd-in}

Regarding the effect of an exogenous increase in immigrant labor supply on native college demand, I estimate this parameter under the assumptions of no correlated, exogenous shifts in labor demand $(\dot{\zeta}=0)$, college supply $(\dot{\varphi}=0)$, native and immigrant college demand $\left(\dot{\mu}^{N}=\dot{\mu}^{I}=0\right)$, and native labor supply $\left(\dot{\nu}^{N}=0\right)$.

It can be derived, given prior assumptions and definitions, that $\dot{\xi}=\left[\pi^{I}-\left(\frac{\lambda}{1+\lambda}\right)(\Omega \Delta \Gamma) \pi^{I}\right] \dot{\nu}^{I} \equiv$ $\Psi \dot{\nu}^{I}{ }^{54}$ Also recall, related to equation (7), that $\dot{d}_{E}^{N}=-\phi^{N} \dot{f}-\eta^{N} \dot{w}+\dot{\mu}^{N}$ and $\dot{d}_{E}^{I}=$ $-\phi^{I} \dot{f}-\eta^{I} \dot{w}+\dot{\mu}^{I}$. Substituting $\Psi \dot{\nu}^{I}$ for $\dot{\xi}$ in equilibrium price equations (12) and (13) and manipulating existing formulations, I derive the following equilibrium equations for native college demand $\dot{d}_{E}^{N}$ and immigrant labor supply $\dot{s}_{L}^{I}$ under the current assumptions:

$$
\begin{gathered}
\dot{d}_{E}^{N *}=\left[\eta^{N} \Psi \Gamma-\phi^{N} \Psi(\Lambda \Delta \Gamma)\right] \dot{\nu}^{I} \\
\dot{s}_{L}^{I *}=\left\{\left(\pi^{N} \gamma^{N}+\theta\right)\left(1-\lambda\left[\eta^{I} \Psi \Gamma-\phi^{I} \Psi(\Lambda \Delta \Gamma)\right]\right)+\lambda \pi^{N} \gamma^{I}\left[\eta^{N} \Psi \Gamma-\phi^{N} \Psi(\Lambda \Delta \Gamma)\right]\right\} \Gamma \dot{\nu}^{I} .
\end{gathered}
$$

The implied crowding parameter of interest is thus defined as:

$$
\beta=\frac{\dot{d}_{E}^{N *} / \dot{\nu}^{I}}{\dot{s}_{L}^{I *} / \dot{\nu}^{I}}=\underbrace{\frac{1}{h(.)}}_{-\epsilon_{w L}} \eta^{N}+\underbrace{\frac{\Lambda \Delta}{h(.)}}_{-\epsilon_{f L}} \phi^{N} \in[0, \infty),
$$

where $h($.$) is a complicated function of the structural parameters, while \epsilon_{w L}$ and $\epsilon_{f L}$ are elasticities of relative unskilled wages and tuition/fees (respectively) to exogenous inflows

\footnotetext{
${ }^{54}$ This follows in part from the fact that, given $\dot{\nu}-\lambda \dot{d}_{E}^{*}=\dot{\xi}=\pi^{N} \dot{\xi}^{N}+\pi^{I} \dot{\xi}^{I}$ from equations (10) and (11), it can be shown that in general $\dot{\nu}=\pi^{N} \dot{\nu}^{N}+\pi^{I} \dot{\nu}^{I}$.
} 
of relatively unskilled immigrant labor. ${ }^{55}$ The lower bound on $\beta$ occurs for any of several scenarios, including: (a) perfectly elastic labor demand $(\theta \rightarrow \infty)$, (b) perfectly inelastic college supply $(\psi=\kappa=0)$, (c) very small immigrant population shares $\left(\pi^{I} \rightarrow 0\right)$, or (d) frictionless mobility across states or highly wage-sensitive within-state labor supply $\left(\gamma^{I}\right.$ or $\left.\gamma^{N} \rightarrow \infty\right)$. The upper bound on $\beta$ requires the opposite extreme on all elements (a)-(d): that is, perfectly inelastic labor demand, perfectly elastic college supply, very large immigrant population shares, and immobile labor with no labor supply sensitivity to wage changes.

The sign of $\beta$ shows that relatively unskilled immigrant labor inflows weakly increase (that is, crowd in) native college enrollment, and the magnitude of this reduced-form effect is a function of the sensitivity of native college demand to changes in wages and tuition/fees, as well as the sensitivity of those market prices to the immigrant inflows.

\section{Crowd-out}

Turning now to the effect of an exogenous increase in immigrant college demand on native college demand, I estimate this parameter under the assumptions of no correlated, exogenous shifts in labor demand $(\dot{\zeta}=0)$, college supply $(\dot{\varphi}=0)$, native and immigrant labor supply $\left(\dot{\nu}^{N}=\dot{\nu}^{I}=0\right)$, and native college demand $\left(\dot{\mu}^{N}=0\right)$.

It can be determined, given prior assumptions and definitions, that $\dot{\xi}=\left[-\left(\frac{\lambda}{1+\lambda}\right)(\psi \Delta) \pi^{I}\right] \dot{\mu}^{I} \equiv$ $\Phi \dot{\mu}^{I}$. Again recall, related to equation (7), that $\dot{d}_{E}^{N}=-\phi^{N} \dot{f}-\eta^{N} \dot{w}+\dot{\mu}^{N}$ and $\dot{d}_{E}^{I}=$ $-\phi^{I} \dot{f}-\eta^{I} \dot{w}+\dot{\mu}^{I}$. Substituting $\Phi \dot{\mu}^{I}$ for $\dot{\xi}$ in equilibrium price equations (12) and (13) and manipulating existing formulations, I derive the following equilibrium equations for native college demand $\dot{d}_{E}^{N}$ and immigrant college demand $\dot{d}_{E}^{I}$ under the current assumptions:

$$
\begin{gathered}
\dot{d}_{E}^{N *}=\left\{\eta^{N} \Phi \Gamma-\phi^{N}[\Delta+(\Lambda \Delta \Gamma) \Phi]\right\} \dot{\mu}^{I}, \\
\dot{d}_{E}^{I *}=\left\{1+\left(\eta^{I} \Phi \Gamma-\phi^{I}[\Delta+(\Lambda \Delta \Gamma) \Phi]\right)\right\} \dot{\mu}^{I} .
\end{gathered}
$$

The implied crowding parameter of interest is thus defined as:

$$
\alpha=\frac{\dot{d}_{E}^{N *} / \dot{\mu}^{I}}{\dot{d}_{E}^{I *} / \dot{\mu}^{I}}=\underbrace{\frac{\Phi \Gamma}{l(.)}}_{-\epsilon_{w E}} \eta^{N}+\underbrace{\frac{(\Delta+\Lambda \Delta \Gamma \Phi)}{l(.)}}_{-\epsilon_{f E}} \phi^{N} \in[-1,0],
$$

where $l($.$) is a complicated function of the structural parameters, while \epsilon_{w E}$ and $\epsilon_{f E}$ are elasticities for the sensitivity of relative unskilled wages and tuition/fees (respectively) to exogenous inflows of immigrant students. ${ }^{56}$ The upper bound on $\alpha$ occurs when there is perfectly elastic college supply with respect to tuition/fees $(\psi \rightarrow \infty)$ combined with any of several scenarios, including: (a) perfectly elastic labor demand $(\theta \rightarrow \infty)$, (b) frictionless mobility across states or highly wage-sensitive within-state labor supply $\left(\gamma^{I}\right.$ or $\left.\gamma^{N} \rightarrow \infty\right)$, (c) very small immigrant population shares $\left(\pi^{I} \rightarrow 0\right)$, or $(\mathrm{d})$ no retention

\footnotetext{
${ }^{55}$ In other words, $\epsilon_{w L}=\frac{\dot{w}^{*} / \dot{\nu}^{I}}{\dot{s}_{L}^{I *} / \dot{\nu}^{I}}$ and $\epsilon_{f L}=\frac{\dot{f}^{*} / \dot{\nu}^{I}}{\dot{s}_{L^{*}}^{I *} \dot{\nu}^{I}}$.

${ }^{56}$ In other words, $\epsilon_{w E}=\frac{\dot{w}^{*} / \dot{\mu}^{I}}{\dot{d}_{E}^{I^{*}} / \dot{\mu}^{I}}$ and $\epsilon_{f E}=\frac{f^{*} / \dot{\mu}^{I}}{\dot{d}_{E}^{I *} / \dot{\mu}^{I}}$.
} 
of college students in the state's labor market $(\lambda=0)$. Conversely, the lower bound on $\alpha$ simply requires perfectly inelastic college supply with respect to tuition/fees.

The sign of $\alpha$ shows that immigrant student inflows weakly decrease (that is, crowd out) native college enrollment, and the magnitude of this reduced-form effect is once again a function of the sensitivity of native college demand to changes in wages and tuition/fees, as well as the sensitivity of those market prices to the immigrant inflows. The magnitude range of - 1 to 0 also aligns with theory and findings of other immigrant-native displacement studies (Hoxby 1998; Card 2001; Cortes 2008).

\section{Implications for Estimation}

Although already discussed in the paper, I highlight again the key estimation issues and guidelines, now with reference to the formal model.

First, both coefficients focus on how exogenous, unobserved immigrant shifts affect native college enrollment via observed immigrant quantities for relatively unskilled labor supply and college demand. Thus, the regressors of interest in the estimating equation should also be focused on immigrants. It should be noted that when the focus of the model is, alternatively, how exogenous immigrant shifts affect native college enrollment via observed total quantities for relatively unskilled labor supply and college demand, the parameter results are qualitatively similar. When considering total quantities, the noteworthy changes are that: (a) the level of immigrant inflows (via $\pi^{I}$ ) no longer factors into the formula for $\beta$ (crowd-in); and (b) the lower bound of $\alpha$ (crowd-out) decreases from -1 to $-\infty$.

Second, compared with the graphical representation, the formal model makes it explicitly clear that the relative magnitudes of the crowd-in and crowd-out parameters are ambiguous, as both $|\beta|>|\alpha|$ and $|\beta|<|\alpha|$ are possible depending on structural parameter values.

Third, changes in several parameters (for example, increases in labor demand elasticity, $\theta$ ) will cause both $\beta$ and $\alpha$ to tend toward 0 . However, there are exceptions to this. Moreelastic college supply with respect to tuition/fees, $\psi$, as well as a lower percentage of a state's college students retained for the labor market, $\lambda$, both reduce the magnitude of $\alpha$, whereas they increase or have an ambiguous effect, respectively, on the magnitude of $\beta .{ }^{57}$

Fourth, the model motivates the need for independent and dependent variables in the estimating equation that are specified in logs, given that the parameters in equations (18) and (21) are for log changes.

Fifth, given that it is always assumed that there are no exogenous increases in native college enrollment $\left(\dot{\mu}^{N}=0\right)$, it is necessary to account for native demographic shocks that would otherwise affect their college demand. This can be accomplished by examining log changes in enrollment rates rather than enrollment levels.

Finally, appropriate estimation is necessary to ensure that other assumptions about the lack of confounding market shifts — for example, in labor demand $(\dot{\zeta}=0)$ and college supply $(\dot{\varphi}=0)$ - actually hold. To accomplish this, I utilize a procedure to

\footnotetext{
${ }^{57}$ Additionally, although absent from this static model, in reality the different time horizons for the crowd-in and crowd-out effects due to the lag between college enrollment and labor market entry could also open a role for native expectations and uncertainty to explain differences in the coefficient magnitudes.
} 
estimate immigrant college demand and use 2SLS estimation, various fixed effects, ${ }^{58}$ and an estimating equation specified in first differences.

\section{Latent Variable Model of Immigrant College Demand}

This model, using a latent variable framework, describes in further detail the underlying background and identification assumptions behind the estimation in section 4 , to predict immigrant student and labor inflows.

For any immigrant $i$, let

$$
\begin{aligned}
& y_{i}^{*} \equiv \text { college demand (latent) } \\
& y_{i} \equiv \text { college-enrolled (observed), where }
\end{aligned}
$$

$$
y_{i}^{*}=\mathbf{x}_{i}^{\prime} \boldsymbol{\vartheta}+\varepsilon_{i},
$$

and

$$
y_{i}=\left\{\begin{array}{ll}
1 & \text { if } y_{i}^{*}>0 \\
0 & \text { if } y_{i}^{*} \leq 0
\end{array} .\right.
$$

$\mathbf{x}_{i}^{\prime}$ is a vector of individual characteristics (for example, age - see section 4 for details), $\varepsilon_{i}$ is the mean-zero error term, and $y_{i}^{*}$ can be thought of as the difference between an individual's marginal value of college enrollment and equilibrium tuition/fees. Further allowing for differential observations and innovations by state $j$ yields

$$
y_{i j}^{*}=\mathbf{x}_{i j}^{\prime} \boldsymbol{\vartheta}+\varepsilon_{i j},
$$

where

$$
\varepsilon_{i j}=\delta_{i j}+\underbrace{\omega_{j}+\varphi_{j}}_{\text {market shocks }} .
$$

$\omega_{j}=-\zeta_{j}$ is a negative labor demand shock, $\varphi_{j}$ is a positive college supply shock, and $\delta_{i j}$ is the idiosyncratic component of the composite error.

Further using the notation of the earlier Appendix model, $y_{i j}^{*}$ is related to a parameterization of $\dot{d}_{E}^{I}=-\phi^{I} \dot{f}-\eta^{I} \dot{w}+\dot{\mu}^{I}$. The composite error is intended to capture the effects of market price changes, $\dot{f}$ and $\dot{w}$, on immigrant enrollment demand, while the covariates and coefficients are meant to capture the effects of exogenous shifts, $\dot{\mu}^{I}$.

Given that the population of interest is immigrants and not all foreign-born individuals (whether they immigrated or not), non-random sample selection of immigrants into U.S.

\footnotetext{
${ }^{58}$ This includes those at the state level, since effects in the model are theorized for given labor and higher education markets of a fixed size. The empirical analog of this assumption is thus to estimate effects over time within states, while also accounting for any native demographic shocks, as already discussed.
} 
states is not problematic. ${ }^{59}$ Consistent estimation of the $\boldsymbol{\vartheta}^{\prime} \mathrm{s} \Leftrightarrow E\left(x_{i j} \varepsilon_{i j}\right)=0 .{ }^{60}$

\section{Parameters for Native College Demand Elasticities}

As discussed in the paper and Table 10, several assumptions are necessary to derive the native college demand elasticities, described here in detail. Equations (18) and (21) of the model more fully describe the nonlinear system of two equations to be solved for the two unknown college demand elasticities, $\eta^{N}$ and $\phi^{N}$. Because no closed-form solution to the system exists, a numerical solution is determined. There are eleven free parameters from the model whose values need to be assigned: $\eta^{I}, \phi^{I}, \beta, \alpha, \pi^{N}, \gamma^{N}, \gamma^{I}, \kappa, \lambda, \psi$, and $\theta$.

\section{Immigrant College Demand Elasticities}

I make a simplifying assumption that there are no differences in the price sensitivities of native and immigrant college demand, so that $\eta^{I}=\eta^{N}$ and $\phi^{I}=\phi^{N}$. While this is admittedly restrictive, it may be the case that the distributions of natives vs. immigrants across states do not differ systematically with regard to these parameters. More functionally, this assumption allows the exercise to continue without the need to further specify immigrant behavior in the model.

\section{Crowding Elasticities}

I use the crowding estimates $\hat{\beta}$ and $\hat{\alpha}$ from Table 5 , column 7 for $\beta$ and $\alpha$, respectively. For $\hat{\alpha}$, I use the adjusted, crowd-out ratio estimate in place of the coefficient estimate, since the former is more closely aligned with the model, as previously discussed.

\section{Native Population Share}

For $\pi^{N}$, the native share of the total population, I use the native share of the 18-64 population from 1970 to 2000 in the census data.

\section{Labor Supply Elasticities}

The relative labor supply elasticities for natives and immigrants, $\gamma^{N}$ and $\gamma^{I}$, respectively, cannot, however, be similarly observed directly from the census data. To proxy for these variables, I assume that the wage sensitivity of labor supply within-state is the same for natives and immigrants, focusing instead on the wage sensitivity of labor supply between states (that is, the cross-state migration elasticity) and how it differs between the skilled and unskilled. Separately for natives and immigrants, ages 18 to 64 from 1970 to 2000, I calculate the proportion of unskilled individuals who migrated across states in the five years prior to being surveyed, relative to the proportion of skilled individuals who mi-

\footnotetext{
${ }^{59}$ Demand for immigration into particular states can similarly be thought of as a latent variable, $m_{i j}^{*}$, where only binary $m_{i j}$ (immigration into state $j$ ) is observed, and $m_{i j}^{*}=\mathbf{x}_{i j}^{\prime} \boldsymbol{\varrho}+\tau_{i j}$. If $\tau_{i j}$ is a composite error that is similarly a function of shocks $\omega_{j}$ and $\varphi_{j}$, then correlation $\rho_{\varepsilon \tau} \neq 0$, and sample selection bias prevents consistent estimation of the $\varrho$ 's for the foreign-born population via OLS without further corrections. Note that labor demand or college supply shocks having an influence on immigration demand is a sufficient but not necessary condition for $\rho_{\varepsilon \tau} \neq 0$ and the existence of sample selection bias.

${ }^{60} \mathrm{~A}$ violation of this exogeneity condition would occur, for instance, if New York universities added 10,000 additional enrollment seats specifically for non-traditional college students ages 25 and older.
} 
grated across states in the five years prior to being surveyed. I use these ratios as the proxies for $\gamma^{N}$ and $\gamma^{I}$.61

\section{Wage Elasticity of College Supply}

To fix $\kappa$, I assume that college supply is completely wage inelastic.

\section{Retention of College Students in Local Labor Market}

I obtain from Bound et al. (2004) a value for $\lambda$, the share of the endogenous equilibrium change in college-enrolled students who remain in the state's labor market as skilled labor.

\section{Tuition/Fee Elasticity of College Supply}

Multiple values are assigned for $\psi$, the tuition/fee elasticity of college supply, in order to observe how the price elasticities of native college demand change in response. The initial value of $\psi$ is calculated to be inversely related to an estimate from Bound and Turner (2007) for the elasticity of college enrollment with respect to cohort size. ${ }^{62}$ The alternate value of $\psi$ is simply assumed to be larger and more elastic. Recall that the model predicts, other things being equal, that as college supply becomes more elastic, the crowd-in effect increases in magnitude, while the crowd-out effect decreases in magnitude. Thus, as $\psi$ increases, in order to observe given values of $\beta$ and $\alpha$, natives must be increasingly less wage-sensitive and increasingly more tuition/fee-sensitive. Therefore $\eta^{N}$ should decrease in magnitude and $\phi^{N}$ should increase in magnitude.

\section{Elasticity of Substitution}

Multiple values are also assigned for $\theta$, the elasticity of substitution between skilled and unskilled labor, in order to observe how the price elasticities of native college demand change in response. The two chosen values of $\theta$ come from Katz and Murphy (1992) and Card and Lemieux (2001), although it should be noted that their definition of skilled and unskilled differs somewhat from this paper's definition. ${ }^{63}$ Recall that here the model predicts, other things being equal, that as relative labor demand becomes more elastic, both the crowd-in and crowd-out effects decrease in magnitude. Thus, as $\theta$ increases, in order to observe given values of $\beta$ and $\alpha$, natives must be increasingly more wage- and tuition/fee-sensitive. Therefore both $\eta^{N}$ and $\phi^{N}$ should increase in magnitude.

\footnotetext{
${ }^{61}$ Individual observations are weighted using census person weights. For immigrants, the ratio is calculated using only immigrants who have lived in the United States for more than five years. Only information on prior country of residence, rather than cross-state migration activity, is reported in the census for more recent immigrants.

${ }^{62}$ Specifically, I assume $\psi=\frac{x}{1-x}$, where $x \in[0,1]$ is the Bound and Turner (2007) estimate, equal to 0.79 . This ensures that $\psi \in[0, \infty)$ and is positively correlated with $x$. This proxy is an exogenous simplification of the true relationship between $\psi$ and $x$, where $\psi$ is a complicated, endogenous function of $x, \phi^{N}, \eta^{N}, d_{E}, \mu$, and $w$ (parameters from equations (7) and (8)) with some components whose values are difficult to proxy (for example, $\dot{\mu}, \log$ changes in shocks to college demand).

${ }^{63}$ For this exercise, I opt for the Card and Lemieux (2001) estimate from their males-only sample rather than their estimate from the sample pooling men and women. While the latter is more comparable to this paper's sample, the former differs from Katz and Murphy (1992) more starkly and so is more illustrative.
} 


\section{Additional Analyses}

Table A1: Immigrant Covariate Averages in 1960, by College Enrollment Status

\begin{tabular}{|c|c|c|c|c|}
\hline & $\begin{array}{l}\text { All } \\
\text { (1) }\end{array}$ & $\begin{array}{c}\text { College- } \\
\text { Enrolled }[\mathrm{CE}] \\
(2)\end{array}$ & $\begin{array}{c}\text { Not College- } \\
\text { Enrolled [NCE] } \\
(3)\end{array}$ & $\begin{array}{c}\Delta_{C E-N C E} \\
(4)\end{array}$ \\
\hline Age & $\begin{array}{c}46.84 \\
(12.74)\end{array}$ & $\begin{array}{l}22.92 \\
(4.05)\end{array}$ & $\begin{array}{c}47.10 \\
(12.55)\end{array}$ & $\begin{array}{c}-24.181 \\
(0.167)^{* * *}\end{array}$ \\
\hline Female & $\begin{array}{c}0.53 \\
(0.50)\end{array}$ & $\begin{array}{c}0.33 \\
(0.47)\end{array}$ & $\begin{array}{c}0.53 \\
(0.50)\end{array}$ & $\begin{array}{c}-0.201 \\
(0.019)^{* * *}\end{array}$ \\
\hline White non-Hispanic & $\begin{array}{c}0.84 \\
(0.36)\end{array}$ & $\begin{array}{c}0.71 \\
(0.46)\end{array}$ & $\begin{array}{c}0.84 \\
(0.36)\end{array}$ & $\begin{array}{c}-0.138 \\
(0.018)^{* * *}\end{array}$ \\
\hline Black non-Hispanic & $\begin{array}{c}0.01 \\
(0.11)\end{array}$ & $\begin{array}{c}0.04 \\
(0.19)\end{array}$ & $\begin{array}{c}0.01 \\
(0.11)\end{array}$ & $\begin{array}{c}0.023 \\
(0.007)^{* * *}\end{array}$ \\
\hline Asian non-Hispanic & $\begin{array}{c}0.03 \\
(0.18)\end{array}$ & $\begin{array}{c}0.09 \\
(0.28)\end{array}$ & $\begin{array}{c}0.03 \\
(0.18)\end{array}$ & $\begin{array}{c}0.053 \\
(0.011)^{* * *}\end{array}$ \\
\hline Hispanic & $\begin{array}{c}0.11 \\
(0.31)\end{array}$ & $\begin{array}{c}0.13 \\
(0.34)\end{array}$ & $\begin{array}{c}0.11 \\
(0.31)\end{array}$ & $\begin{array}{c}0.028 \\
(0.013)^{* *}\end{array}$ \\
\hline Other & $\begin{array}{l}0.003 \\
(0.05)\end{array}$ & $\begin{array}{l}0.037 \\
(0.19)\end{array}$ & $\begin{array}{l}0.003 \\
(0.05)\end{array}$ & $\begin{array}{c}0.034 \\
(0.007)^{* * *}\end{array}$ \\
\hline Sample probabilities & 1.00 & 0.01 & 0.99 & \\
\hline Observations & 59,084 & 648 & 58,436 & \\
\hline
\end{tabular}

${ }^{*} p<0.10,{ }^{* *} p<0.05,{ }^{* * *} p<0.01$

Notes: Columns (1)-(3) contain covariate means and standard deviations (in parentheses) from the U.S. Census in 1960. Column (4) contains differences in means for enrolled and not-enrolled immigrants and their significance levels, with heteroskedasticity-robust standard errors in parentheses. 


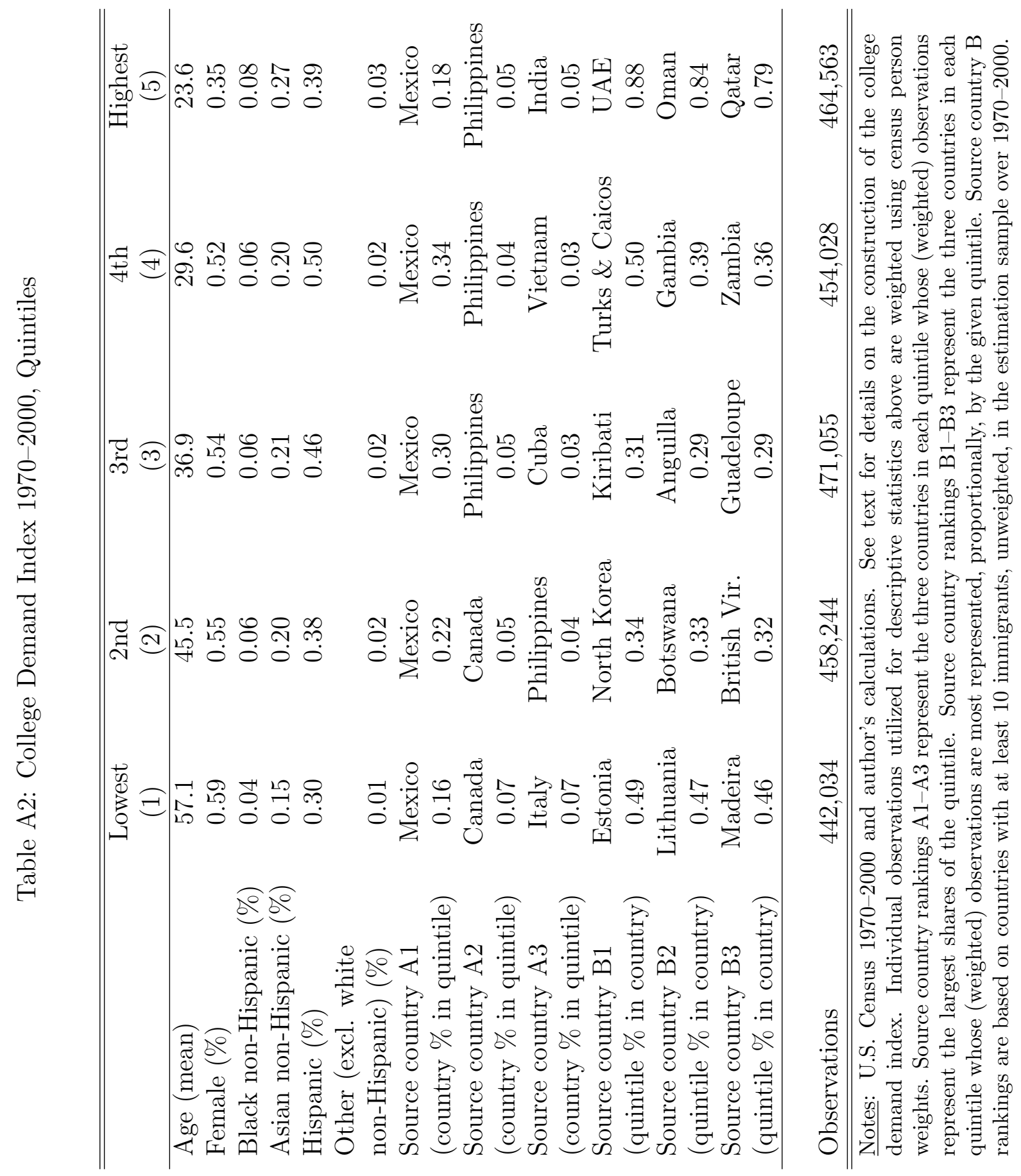

